Journal of Educational

and Psychological Sciences

Volume (6), Issue (7): 28 Feb 2022

P: 107 - 130

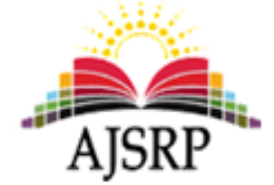

ISSN: 2522-3399

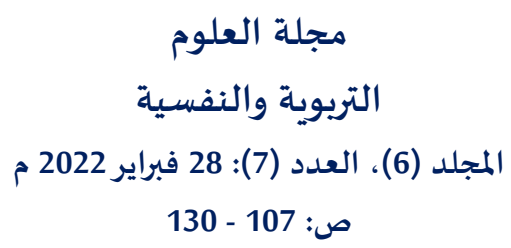

مجلة العلوم

التربوية والنفسية

ص: 107 - 130

\title{
The reality and aspirations of distance learning among students of the ninth grade in the humanities in light of the Corona pandemic in the village of Abu Ghosh from the students' point of view
}

\author{
Nora Yacob Alhaj Othman \\ Mohammad Omran Salha \\ Arab American University || Palestine
}

\begin{abstract}
This study aimed to identify the views of the ninth graders on reality and aspirations for distance learning in light of the Corona pandemic in the village of Abu Ghosh, and the relationship between them. As well as to identify the role of the study variables (gender, subject, level of education of the father and mother), the researchers used the descriptive correlative approach. To achieve the goal of the study, a questionnaire consisting of (6) axes of (40) paragraphs was developed, and its validity and stability coefficient were confirmed. The questionnaires were collected, encoded, entered into the computer and statistically processed using the Statistical Package for Social Sciences (SPSS), and then distributed to an intentional sample of (60) students from the ninth grade students in the village. The results of the study showed that the arithmetic mean of the field of reality was (2.17) with a percentage of (72.2) with a rating (average), and the arithmetic mean of the field of aspirations towards learning was (2.24) and a percentage of (74.7) with a rating (high). It was also found that there are no statistically significant differences in the reality and aspirations of distance learning due to the variable (gender, academic subject, level of education of the father and mother). As well as the existence of a statistically significant relationship between reality and aspirations for distance learning. In light of the results, it is recommended: to encourage and help parents for their children in providing other educational media in addition to simultaneous education; Towards historical and civic documentaries. It is also recommended to promote the generalization of the distance learning strategy after the end of the Corona virus crisis to achieve qualitative leaps in the educational system, by investing the advantages of distance learning in virtual classrooms to apply them in traditional classrooms.
\end{abstract}

Keywords: Covid-19 pandemic, online learning, social sciences.

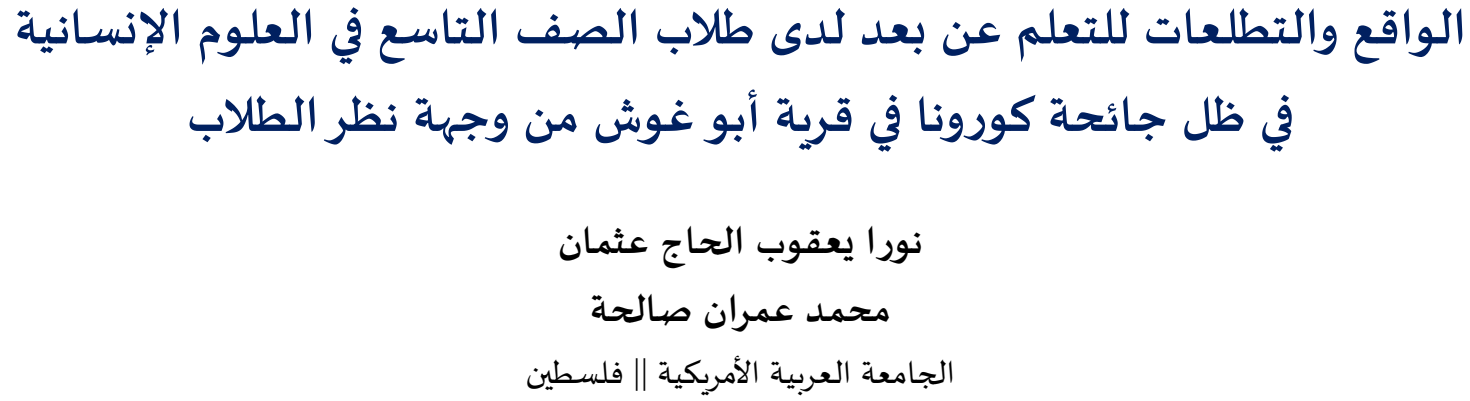

المستخلص: هدفت هذه الدراسة إلى التعرف على وجهات نظر طلاب الصف التاسع على الواقع والتطلعات للتعلم عن بعد في ظل جائحة كورونا في قرية أبو غوش، وعن العلاقة ما بينهم. كذلك للتعرف على دور متغيرات الدراسة (الجنس، المادة الدراسية، مستوى

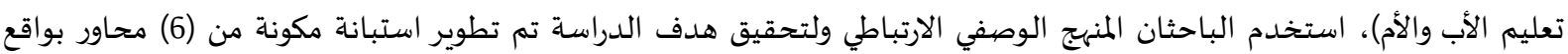


(40) فقرة وتم التأكد من صدقها، ومعامل ثباتها، وبعد عملية جمع الاستبيانات تم ترميزها وإدخالها للحاسوب ومعالجتها إحصائيا

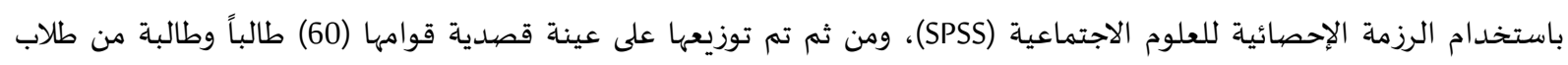

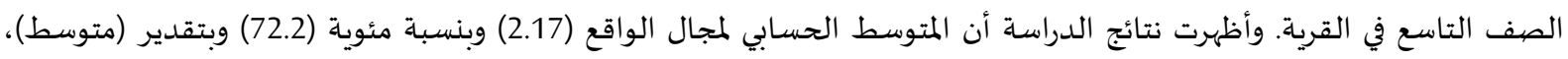

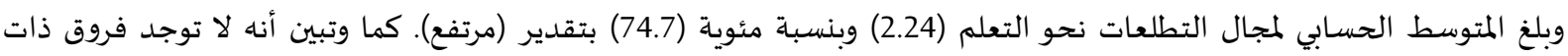

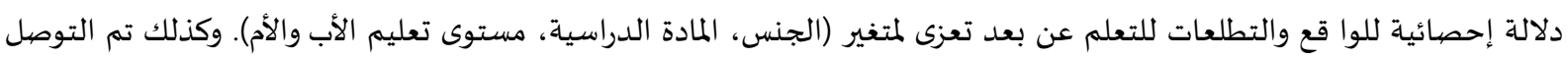

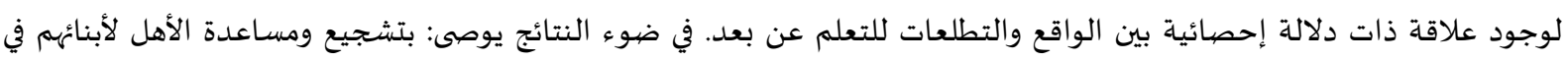

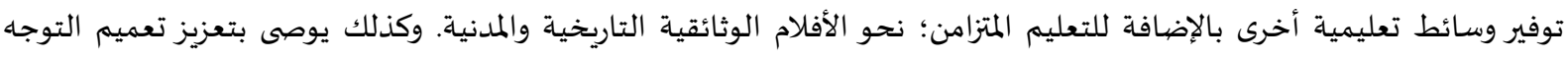

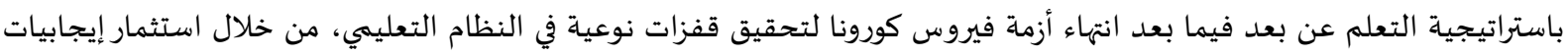
التعلم عن بعد في الفصول الافتراضية لتطبيقها في فصهول الدراسة التقليدية.

الكلمات المفتاحية: جائحة كورونا، التعلم عن بعد، العلوم الإنسانية.

المقدمة.

استيقظ العالم على كابوس جائحة كورونا، عندما أعلنت الصين تفشّي هذا الفيروس القاتل، سريع

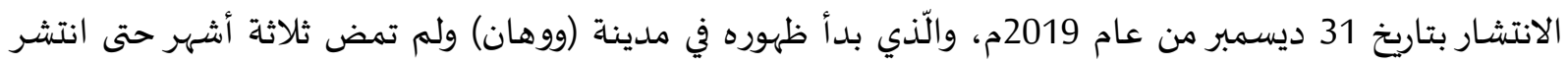

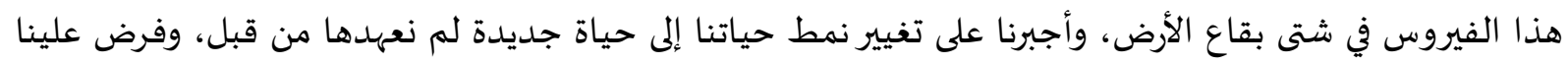

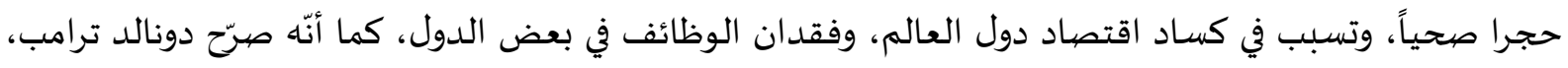

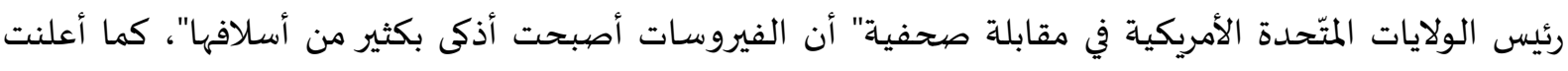
منظمة الصحة العالمية بأن اكتشاف لقاح أو علاج لفيروس كورونا-كوفيد 19- يحتاج وقتاً طويلاً.

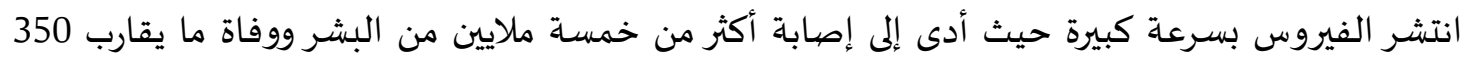

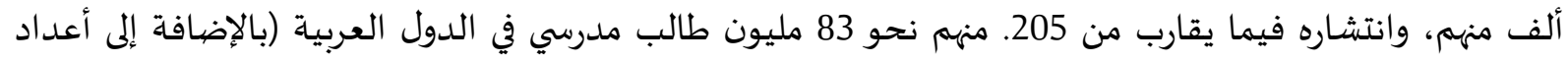

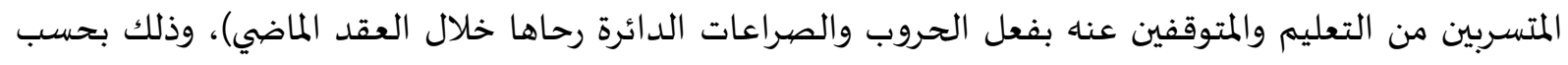

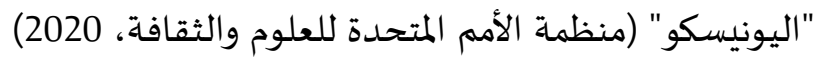

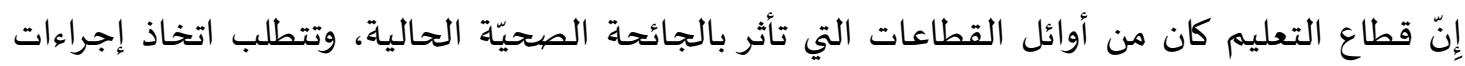

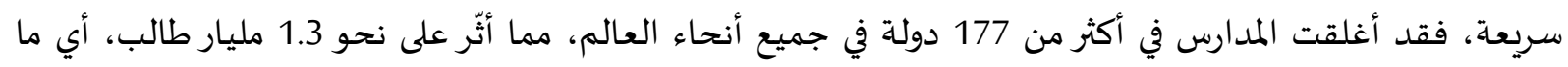

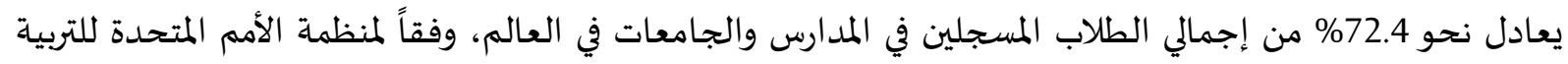
والعلم والثقافة (اليونسكو) وقد ارتبطت أزمة وباء كورونا بإجراءات غير مسبوقة مثل الإغلاق العام في عدد غير قليل من دول العالم

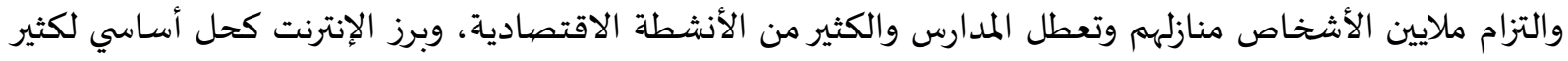

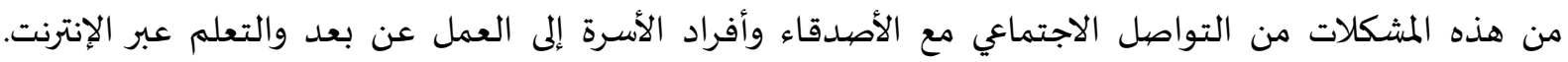
(الدهشان، 2020)

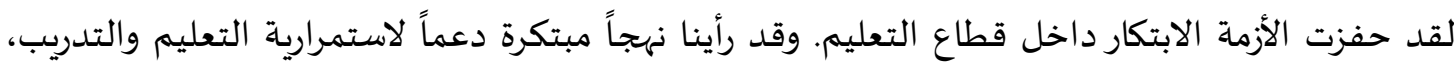

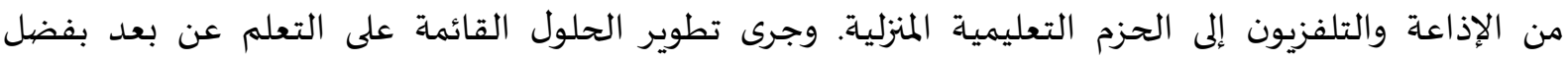

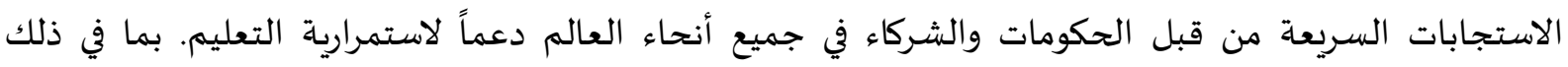

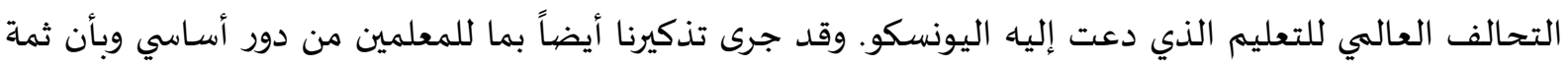

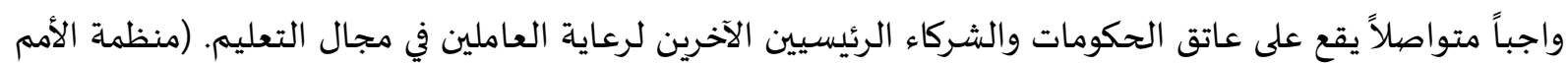

المتحدة، 2020) 
على حد علم الباحثان أنه لا توجد الكثير من الأبحاث والدّراسات التي فحصت الواقع والتّطلعات للتّعليم

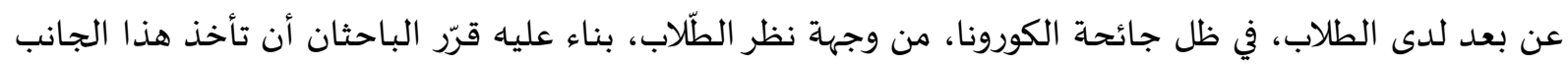

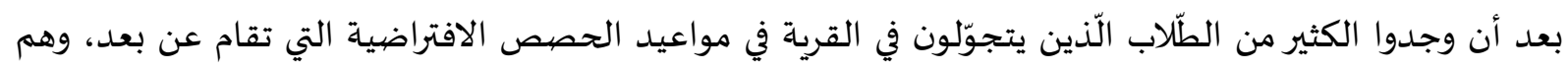

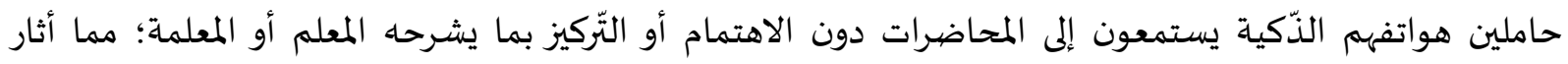
فضرولهما وتساؤلاتهما:

هل هناك تأثير لهذا النّوع من التعليم الجديد على الطلاب؟ وما هي تطلعاتهم نحوه؟ وماهي آثاره الإيجابية أو

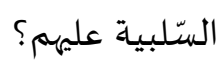

في هذا البحث وجد الباحثان فرصة متاحة؛ لبحث الواقع والتطلعات للتعلم عن بعد بما أنها أصبحت الوسيلة الوحيدة لإنقاذ عملية التعلم والتعليم.

مشكلة الدراسة: جائحة الكورونا خلقت واقعاً جديدا لم نألفه من قبل ومنها الحجر الصبي والعزل المنزلي؛ لتجنب ظاهرة

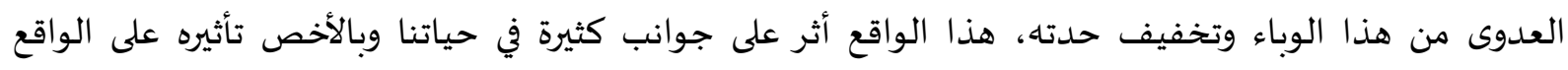
التعليمي، هذا الوضع دفع الجهات المسؤولة عن التعليم بفرض بديل هولئ وهو الاستخدام التكنولوبي في التعلم عن بعد.

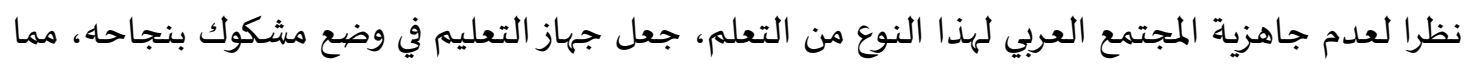
استدعى بعض الباحثين بعمل دراسات في هذا المضمار ومنها دراسة (العتيبي، 2020) التي بحثت عن التعليم عن بعد المداند

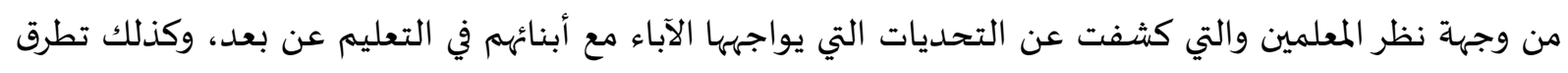

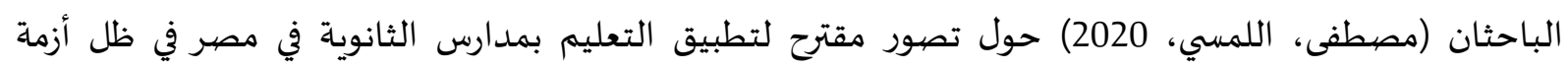
الكورونا.

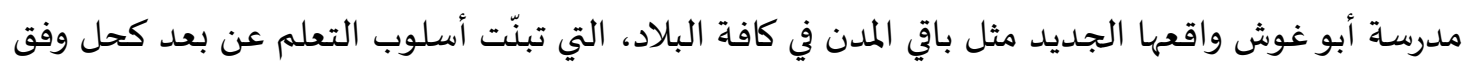
وزارة التّربية والتّعليم؛ من أجل استمرارية عملية التعلم، مع التحديات المرافقة لها مثل: مالميل -

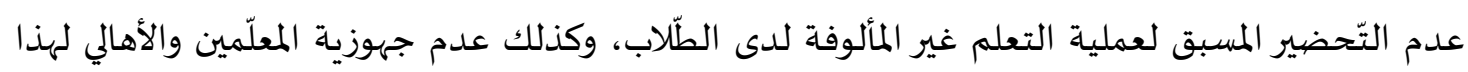
النوع من التعلم.

أسئلة الدراسـة: 1- ما توجهات طلبة الصف التاسع لواقع التعلم عن بعد في العلوم الإنسانية في ظل جائحة كورونا في قرية

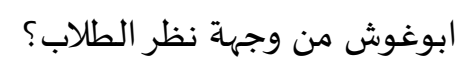

2- ما توجهات طلبة الصف التاسع لتطلعات التعلم عن بعد في العلوم الإنسانية في ظل جائحة كورونا في قرية ابوغوش من وجهة نظر الطلاب؟ 3- هل تختلف وجهات نظر الطلاب في الواقع والتطلعات للتعلم عن بعد في قرية أبو غوش في العلوم الإنسانية في

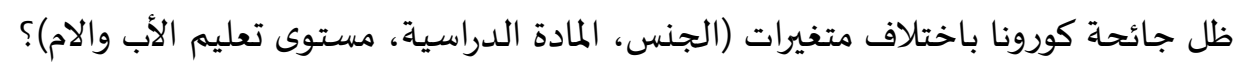

فرضيات الدراسة: للإجابة عن أسئلة الدراسة، صياغة الفرضيات التالية: 
1- لا توجد فروق ذات دلالة إحصائية عند مستوى (0.05) بين متوسطات استجابات الطلاب لواقع التعليم

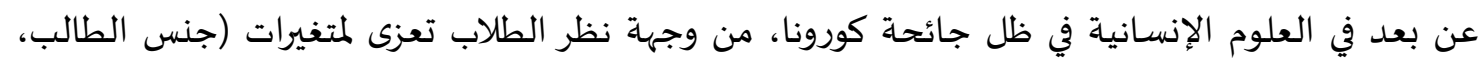
المادة الدراسياة، مستوى تعليم الأب والأم).

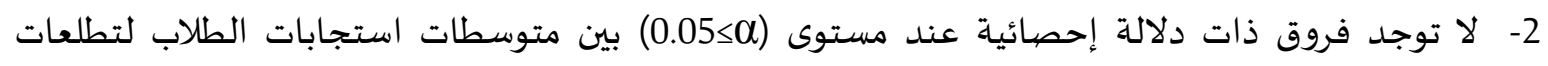

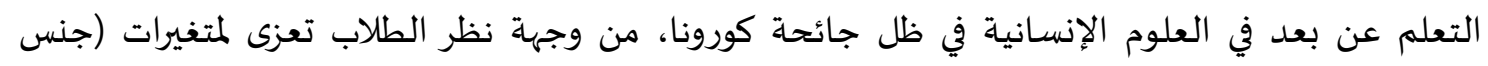
الطالب، المادة الدراسية، مستوى تعليم الأب والأم).

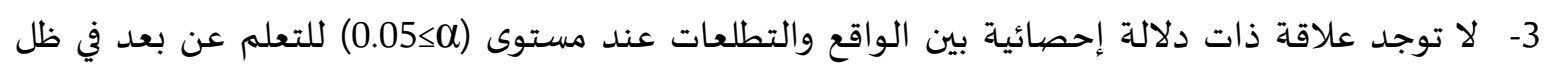
جائحة كورونا، من وجهة نظر الطلاب.

أهداف الدراسة: 1- التعرف على الواقع والتطلعات للتعلم عن بعد لدى طلاب الصف التاسع في العلوم الإنسانية في ظل جائحة

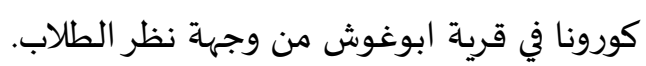

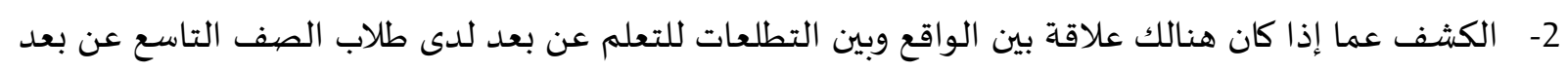

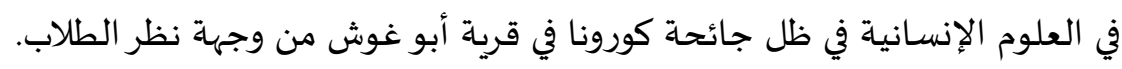

$$
\text { أهمية الدراسة }
$$

- كونها دراسة علمية بحثية استندت إلى دراسات علمية مهمة واستخدمت أداة علمية مقننة التي تؤدي إلى نتائج علمية مهمة. - يأمل الباحثان أن تشكل هذه الدراسة قاعدة معرفية معلوماتية مهمة لدراسات لاحقة.

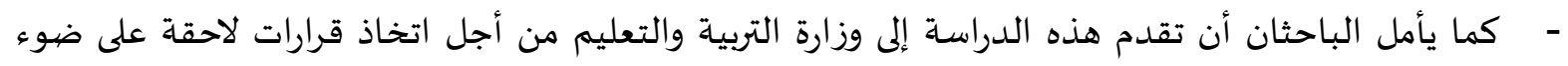
هذه الدراسة.

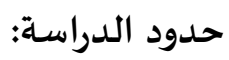
تقتصر نتائج الدراسة على الحدود الآتية:

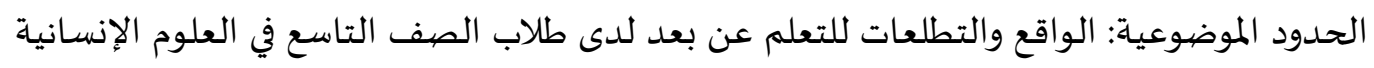
الحدود البشرية: عينة من طلاب الصف التاسع (60 طالبا وطالبة)

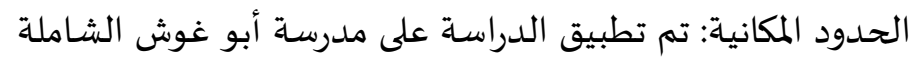

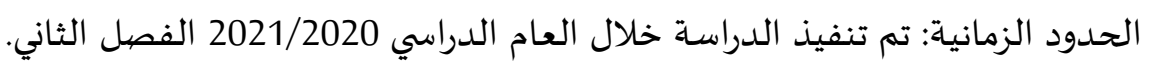

$$
\text { مصطلحات الدراسة: }
$$

- التعليم عن بعد: تعرفه اليونسكو UNESCO: التعليم عن بعد هو الاستخدام المنتظم للوسائط المطبوعة وغيرها

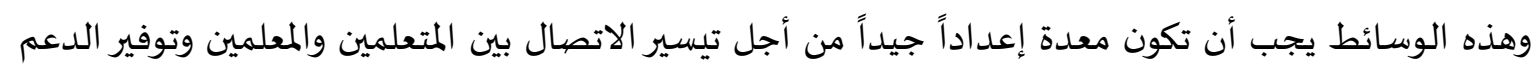
للمتعلمين في دراساتهم. (علي، 2012). م وتعرف إجرائيا بأنها عملية علمية يتم فيها التخطيط والتقويم والتطوير نحو الأفضل يكون فيها المعلم والمتعلم في مكان جغرافي منفصل ويتم التواصل بينهما عن طريق وسائل التواصل الاجتماعي والانترنت وجهاز التلفاز. 
- العلوم الإنسانية: هي مجموعة من النشاطات المعرفية التي تهتم بموضوع الذات الإنسانية من خلال اهتماماتها

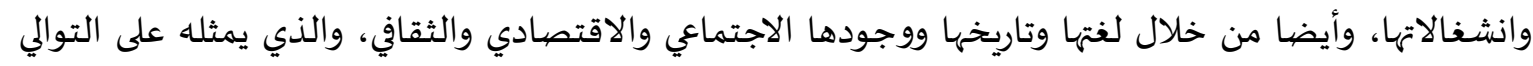

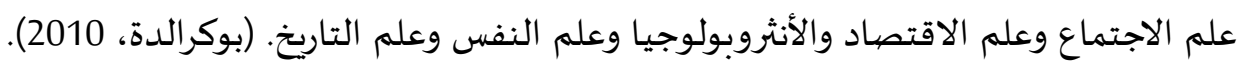

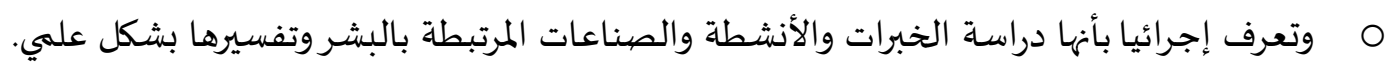

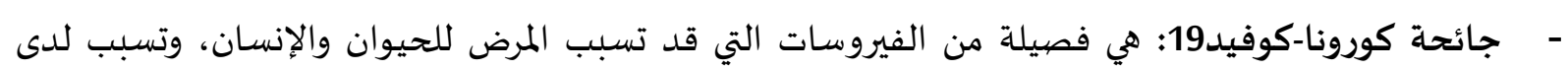

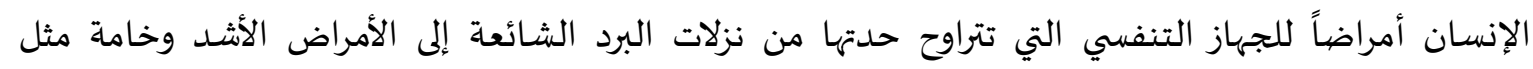

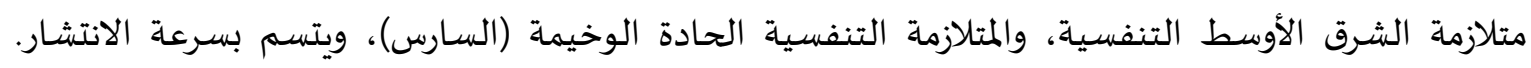
(منظمة الصحة العالمية، 2020). وتعرف إجرائيا بأهها فيروسات خطيرة ومعدية بشكل سريع حيث اجتاحت العت العالم وانتشرت بسرعة بين الناس

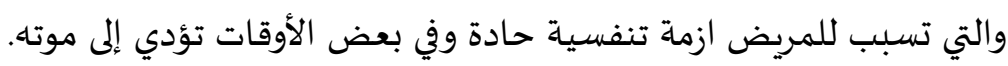

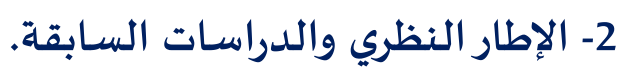

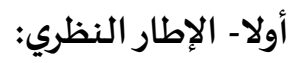

التعلم عن بعد Distance Learning: عرفت دوهمت (1967م) التعليم عن بعد: هو شكل من أشكال الدراسة الذاتية المنظمة يقوم فهيا فريق من المدربين بعمليات إرشاد الطلبة وتقديم المواد التعليمية لهم وتأمين

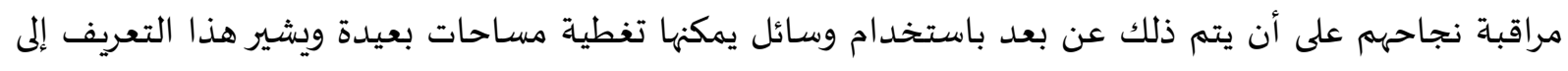

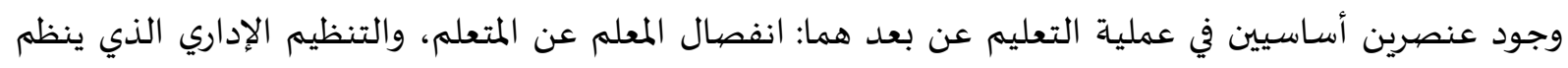

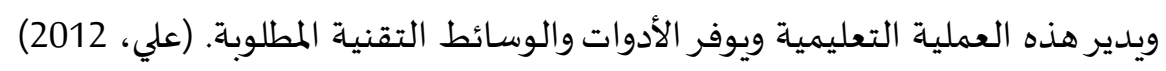

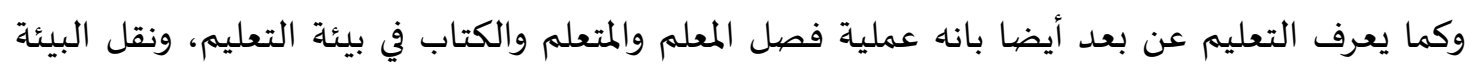
التقليدية من التعليم إلى البيئة الافتراضية منفصلة جغرافيا، وهي ظاهرة حديثة في التعليم وهدفها إعطاء الفرصية

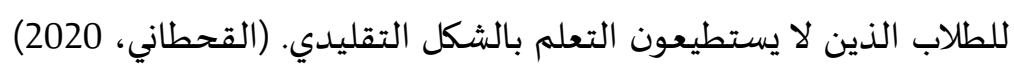

خصيائص التعلم عن بعد: الفصل بشكل كامل بين الطالب والمدرس وبيئة التعليم وحتى زملاء التعليم طيلة فترة الدراسة، ووجود وسيلة اتصال تكنولوجية متطورة بين الطالب والمعلم يتم من خلالها تبادل المهام والواجبات التعليمية، الاعتماد

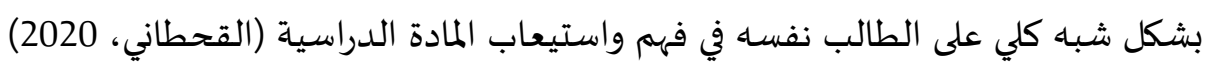
أهمية التعلم عن بعد: يجمع الباحثون والمتخصصيون في الحقل التربوي على أهمية التعلم عن بعد، على أن يكون ملائما لشرائح

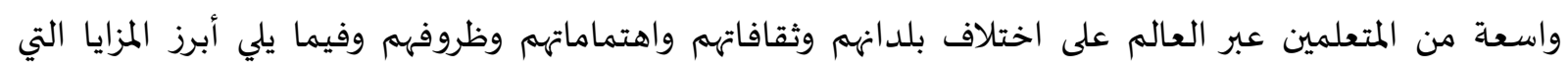

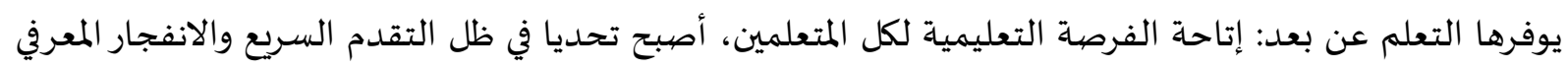

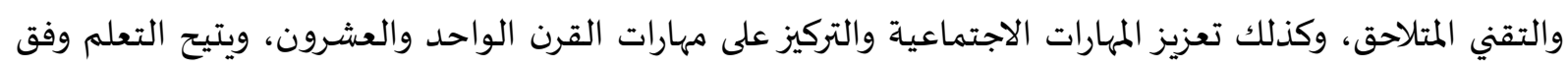

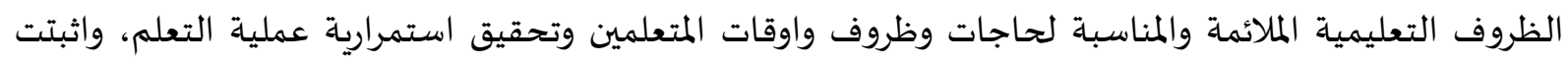

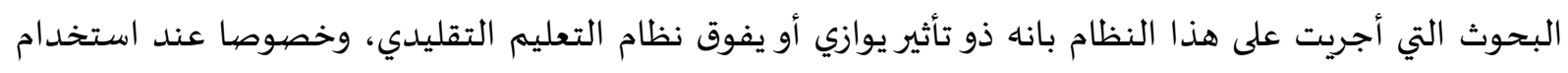
تقنيات التعليم عن بعد والوسائط المتعددة بكفاءة، وانعكاس هذه الإيجابية عل المحتوى التعليهي، بالإضافة إلى الى إنى 
تقديم المناهج للمتعلمين بطرق مبتكرة وتفاعلية، ويتميز هذا النوع من التعليم بانه لا يكلف مبالغ كبيرة من المال. (منظمة الأمم المتحدة، 2020)

\section{التعليم عن بعد في ظل جائحة كورونا:}

لقد قامت وزارة التربية والتعليم في الداخل الفلسطيني بنشر وثيقة للتعليم ما فوق التابت التابدائي وكان هدفها

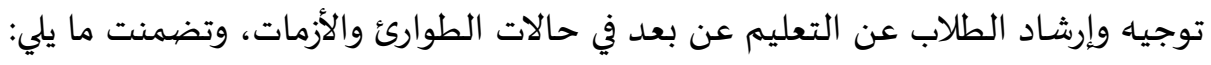

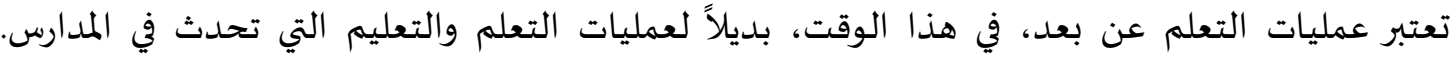

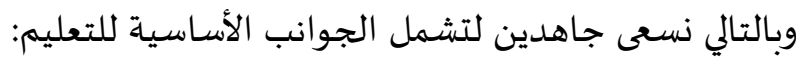
التدريس والتعلم -نقل المادة والمحتوى ونقل المهارات.

الجوانب العاطفية -الدعم، القيم، الشعور بالدافع والقدرة، الأمن في أوقات الأزمات وعدم اليقين وحتى توفير إلى درجة أو أخرى الحاجة الحيوية للمراهقين والمراهقين في الحياة الاجتماعية.

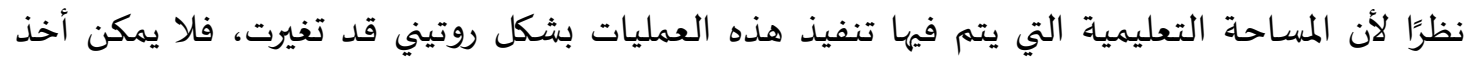

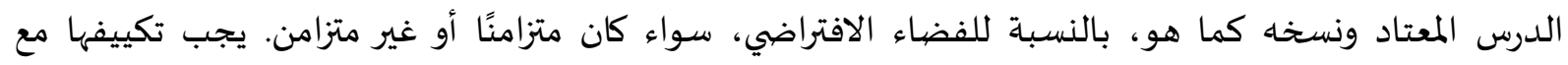

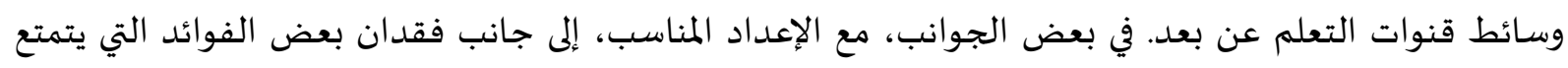

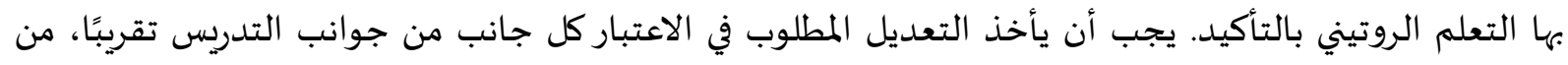
كيفية فتح الدرس أو إغلاقه، وكيفية الحفاظ عليه وتعلم جميع الطلاب وتوقيت ومدة الدرس. لونيل (وزارة التربية والتعليم، 2020)

أهداف التعليم عن بعد في ظل جائحة كورونا من وجهة نظروزارة التربية:

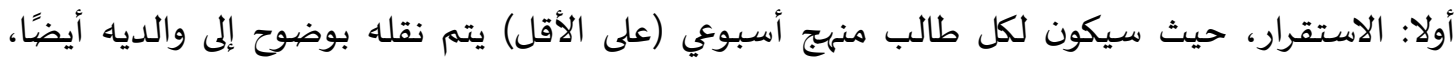
وثانيا: الحضور، سيكون معدل المشاركة في التعلم عن بعد هو نفسـ كما هو الحال في الروتين. وثالثا: الاتصال الشخصي اذ سيحافظ كل طالب على اتصال شخصي منتظم مع شخصية تعليمية من المدرساة. ورابعا :الاتصال

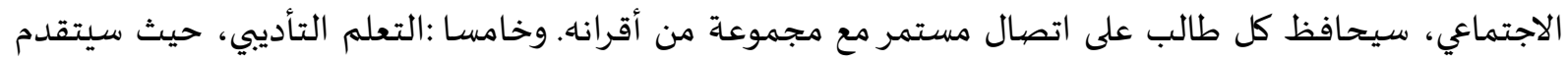

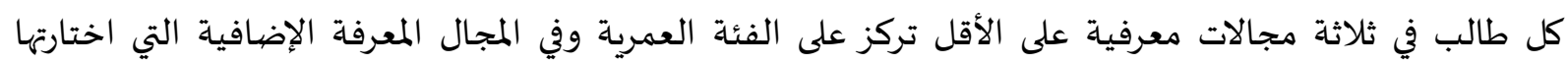

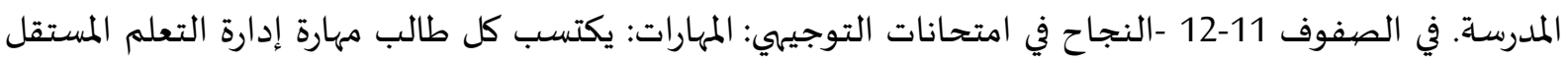
ومحو الأمية الرقمية، والمرونة: كل طالب يواجه صعوبة شخصية بسبب الأوضاع أو لأسباب أخرى سيتلقى استشارة، والاستفادة من فرصة تحسين التربية المدرسية. (وزارة التربية والتعليم، 2020)

\section{Covid-19 فايروس كورونا}

$$
\text { مفهوم فايروس كورونا-كوفيد 19: }
$$

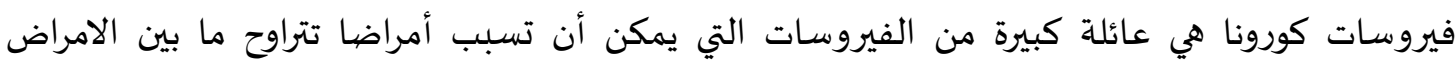

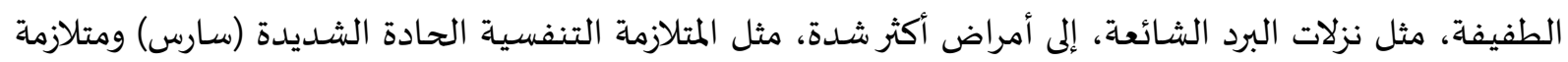
الشرق الأوسط التنفسية (MERS).

ومرض كوفيد-19 يمكن أن يصيب الأطفال والبالغين على حلٍ سواء. ولكن معظم حالات المرض المسجلة هي

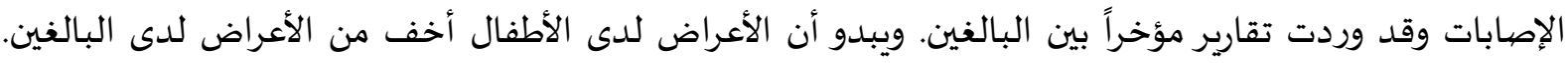


تمثل الأعراض الأكثر شيوعاً لمرض كوفيد-19 في الحمى والإرهاق والسعال الجاف. وتشمل الأعراض الأخرى

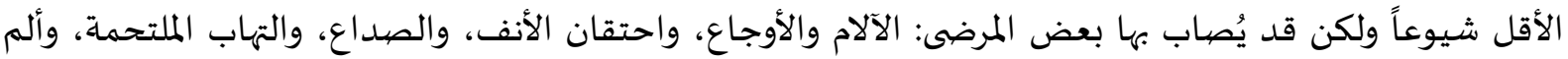

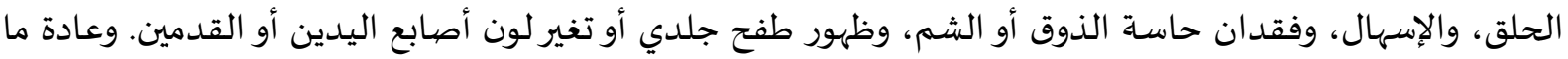
تكون هذه الأعراض خفيفة وتبدأ بشكل تدريجي. ويصاب بعض الناس بالعدوى دون أن يشعروا إلا بأعراض خفيفة جداً. (منظمة الصحة العالمية، 2019)

\section{كيفية انتشار فايروس كورونا-كوفيد19:}

ممكن أن يلتقط الأشخاص عدوى كوفيد-19 من أشخاص آخرين مصابين بالفيروس. وينتشر المرض بشكل أساسي من شخص إلى شخص عن طريق القُطيرات الصغيرة التي يفرزها الشخص المصنصاب بكوفيد-19 من أنفه أو أو فماه عندما يسعل أو يعطس أو يتكلم.. ويمكن أن يلتقط الأشخاص مرض كوفيد-19 إذا تنفسوا هذه القُطيرات من شخص مصاب بعدوى الفيروس. لذلك من المهم الحفاظ على مسافة متر واحد على الأقل (3 أقدام) من الآخرين. وقد تحط هذه القطيرات على الأشياء والأسطح المحيطة بالشخص، مثل الطاولات ومقابض الأبواب ودرابزين

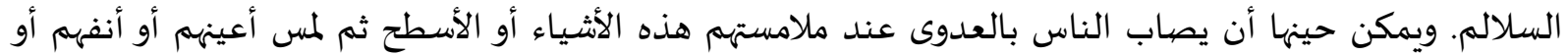
فمهم. لذلك من المهم غسل المواظبة على غسل اليدين بالماء والصابون أو تنظيفهما بمطهر كحولي لفرك الينهاء اليداين.

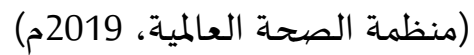

\section{العلاج والوقاية من فايروس كورونا-كوفيد19:}

لقد توصلت بعض الدول في الفترة الأخيرة إلى لقاح لعلاج فايروس كورونا ومن هذه الدول: الولايات المتحدة

الأمريكية، الصين، وروسيا. وأشهرها اللقاحين الأمريكيين الصنع (Moderna) و(Pfizer).

يمكن الوقاية من خطر الإصابة بهذا المرض عن طريق تجنب الخروج من المنزل، وملامسة الأسطح المعدنية، وتجنب المصافحة والعناق مع الآخرين، وتجنب الأماكن المزدحمة، والحفاظ على التباعد الاجتماعي قدر الإمكان، وتغطية الفم والأنف عند العطس والسعال، وغسل اليدين كثيرا بالماء والصابون ولمدة لا تقل عن 20 ثانية، وتنظيف

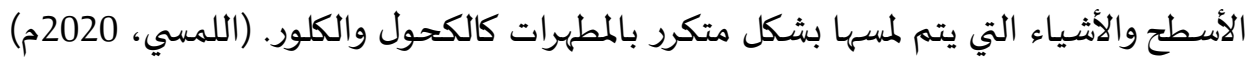

ثانيا- الدراسـات السابقة:

تتميز الدراسة الحالية بتعدد متغيراتها، لذا يعرض الباحثان مجموعاة من الدراسات والبحوث الحديثة

$$
\text { المرتبطة بتلك المتغيرات طبقا للترتيب الابجدي كونها كلها طبقت في نفس السنة السنة. }
$$

- دراسة خطايبة (2020): هدفت الدراسة إلى تعرف وزارة التربية والتعليم الأردنية على اتجاهات طلبة الجامعات

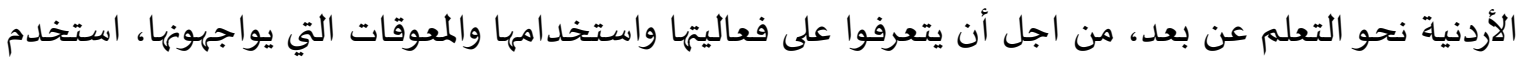
الباحث المنهج التجريبي وتكونت أداة الدراسة من استبانة وتكونت العينة من (57018) طالبا وطالبة موزعين

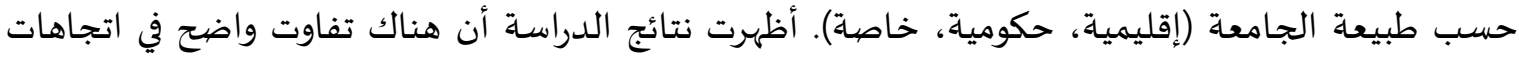
الطلبة نحو التعلم عن بعد، حيث انه يوجد تخوف من قبل الطلاب لاستخدام التعلم عن بعد خاصية أنه التجربة الاولى في تدريس كل المساقات في التعلم عن بعد، اما بالنسبة لمستوى المجالات فان مجال التفاعلية بين الأقران جاء بالمرتبة الأولى ومجال التقييم بالمرتبة الأخيرة كون الطلاب وهيئة التدريس ليس لدئ لديهم خبرة 
بالامتحانات التي تجري باستخدام التقنيات عن بعد. وأهم التوصيات التي أوصى بها الباحث إعادة إجراء الدراسة بعد الانتهاء من الامتحانات النهائية.

دراسة الشديفات (2020): هدفت الدراسة التعرف إلى درجة توظيف التعليم عن بعد بسبب مرض الكورونا في

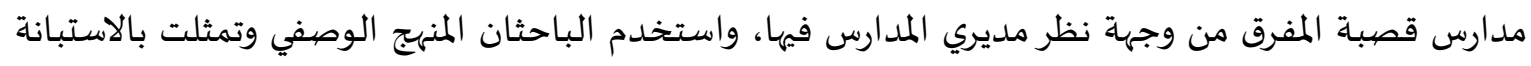

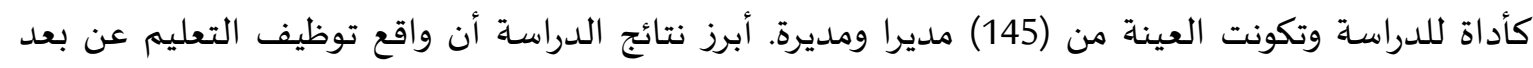

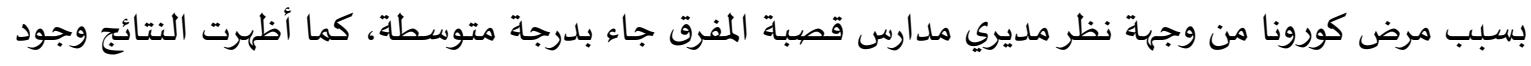

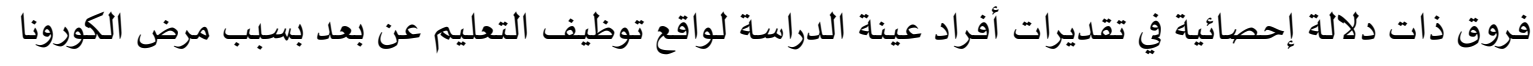

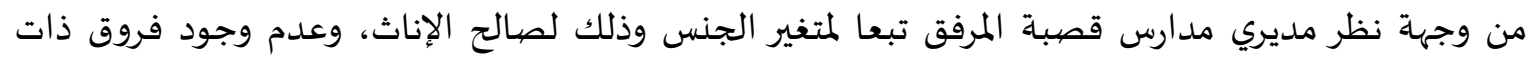

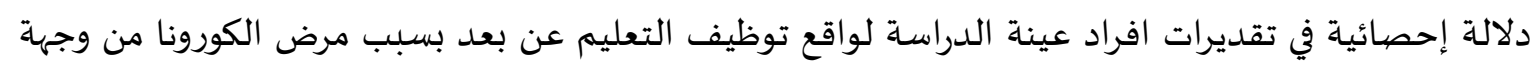
نظر مديري مدارس قصببة المفرق تبعا لمتغير المرحلة الدراسية. دراسة العتيبي (2020): هدفت هذه الدراسة إلى التعرف على التحديات التي واجهت الاسر السعودية في تعليم

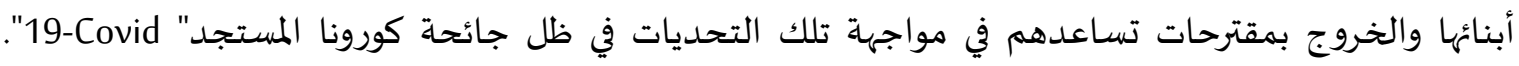

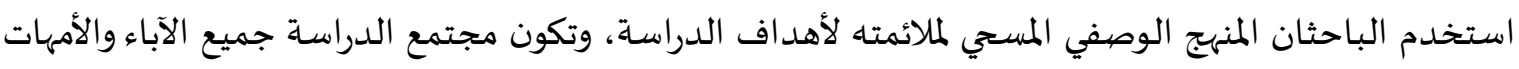

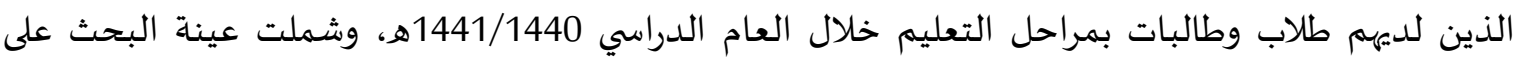

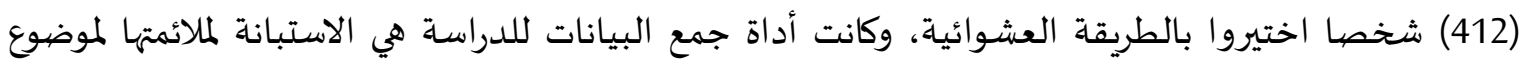

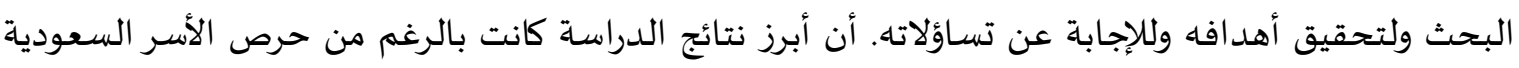

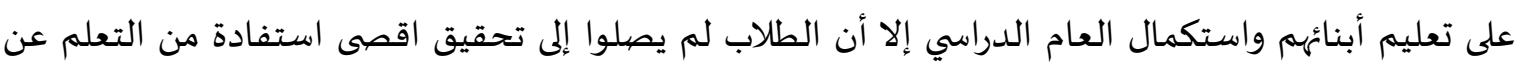

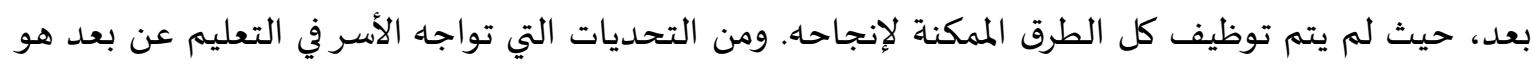

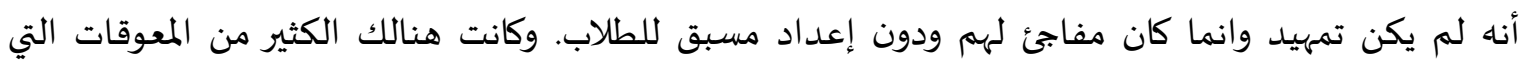

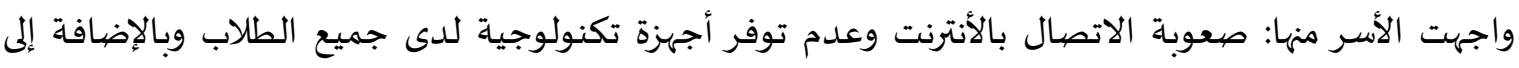

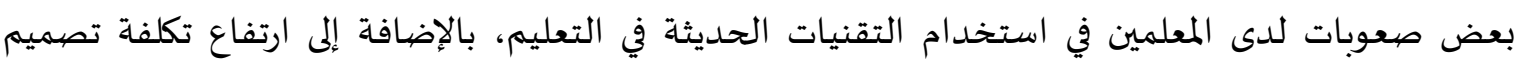

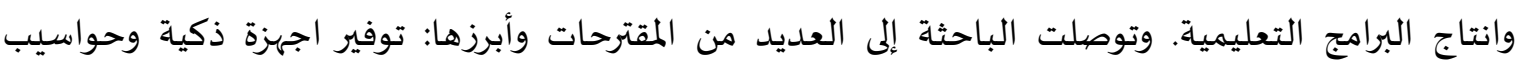

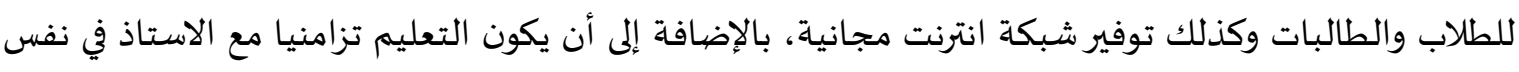
الوقت، كذلك تحسين جودة المواقع التعليمية لتجذب دخول الطلاب اليها.

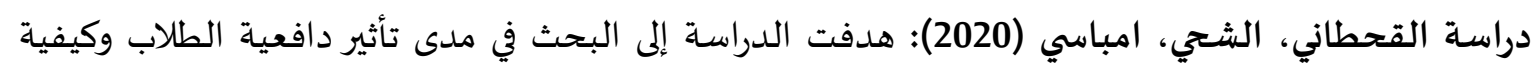

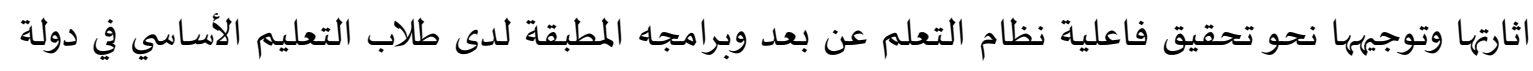

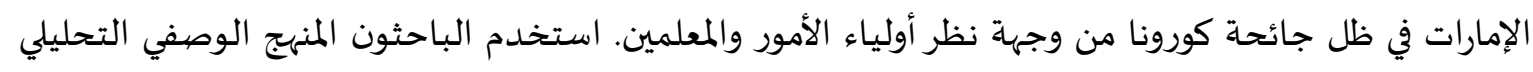

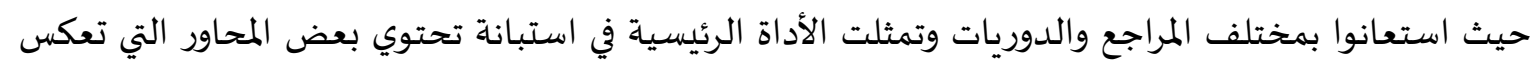

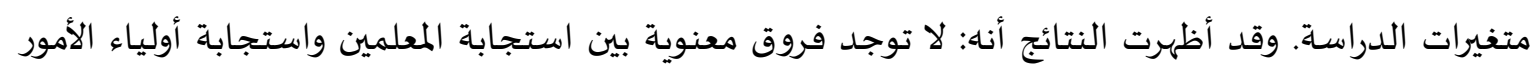

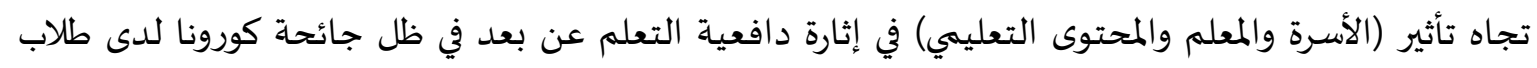

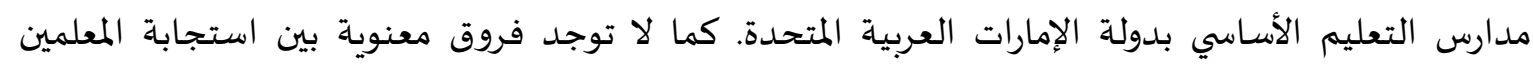

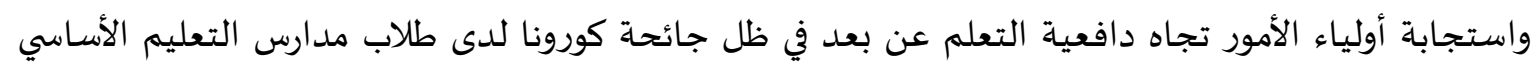
بدولة الإمارات العربية المتحدة. دراسة اللمسي وأحمد (2020): كانت أهداف الدراسة التعرف على تعريف التعليم الهجين وخصيائصيه، بالإضافة على الأسباب والمتغيرات المعاصرة لتطبيق هذا النوع من التعليم في مدارس التعليم الثانوي العام في 
ظل جائحة كورونا المستجد المبا

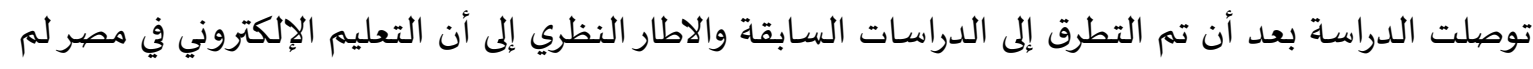

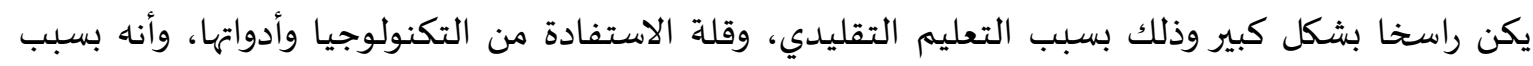

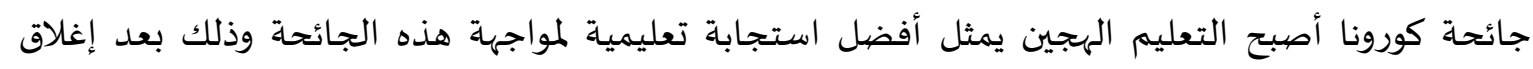

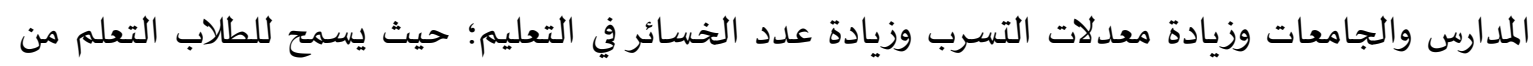

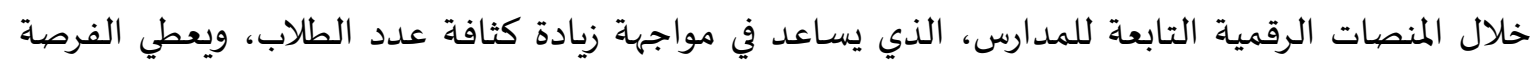
للتعلم عن بعد دون تقييد المحددات الزمانية والمكانية التي كانت بوقت التعليم التقليدي. وأظهاتهات الماتهات النتائج تصورا مقترحا للتعليم الهجين في مصر في ظل جائحة كورونا على ضوء الاستفادة من الدول المتقدمة مثل:

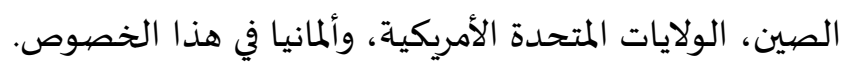

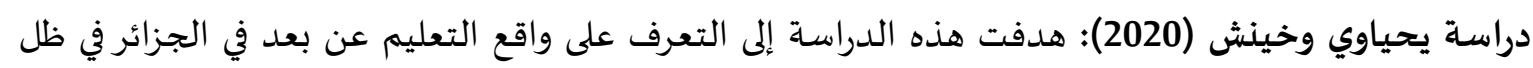

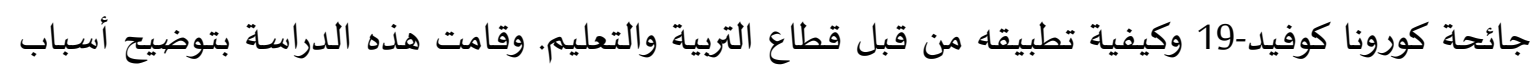

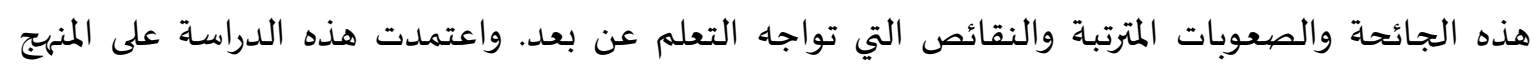

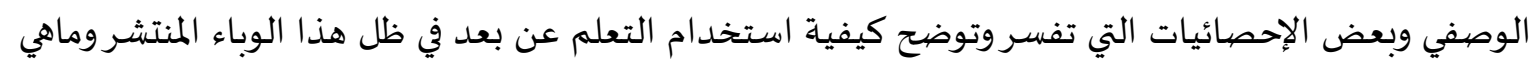

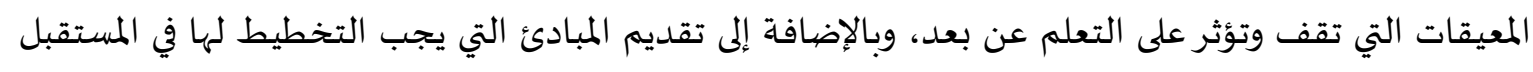

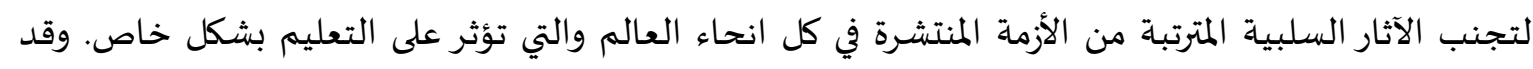

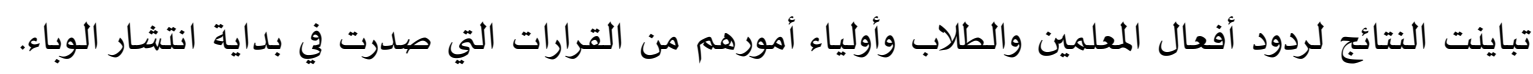

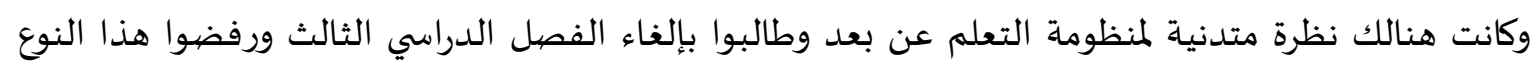

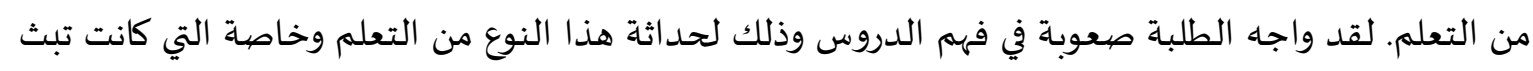
عبر القنوات التلفزيونية. دراسة(Basilaia,Kvavadze, 2020) هدفت الدراسة لمعرفة الآثار الناجمة عن تغير الوضع في التعليم العام في

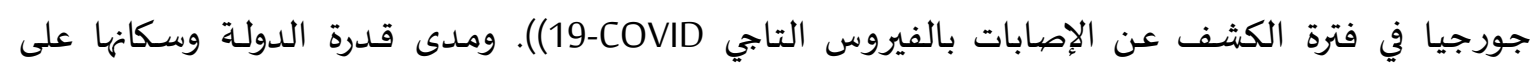

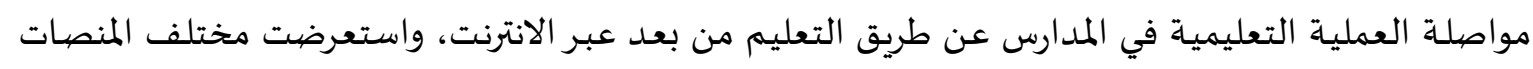

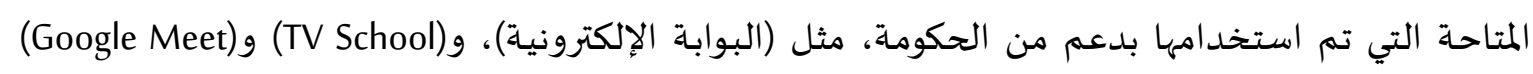

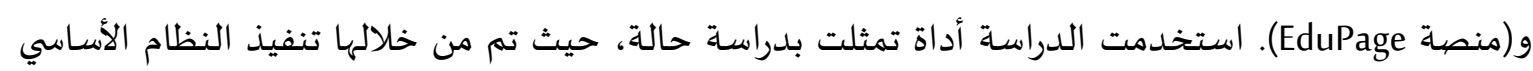

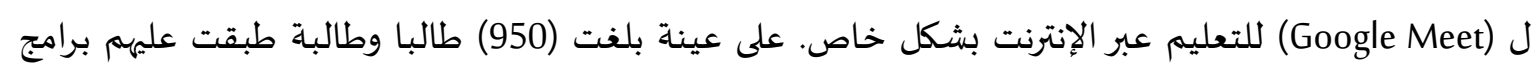

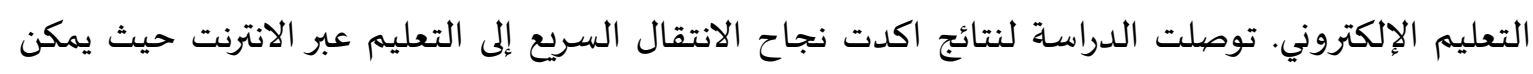

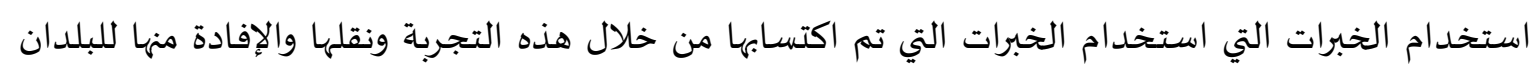

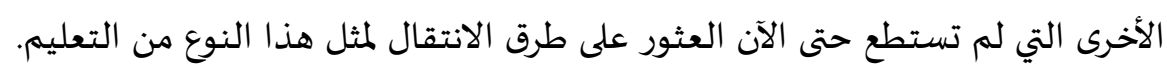

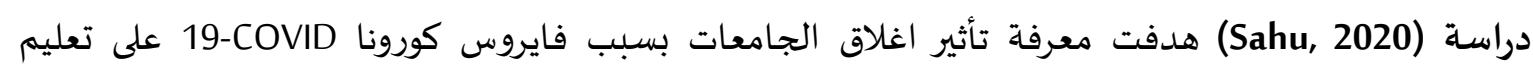

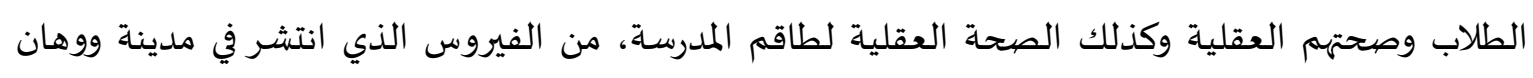

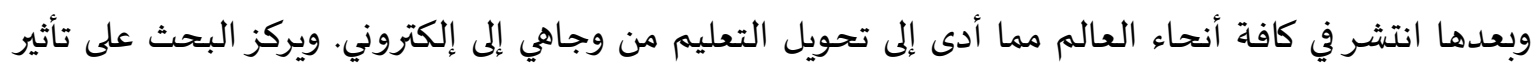

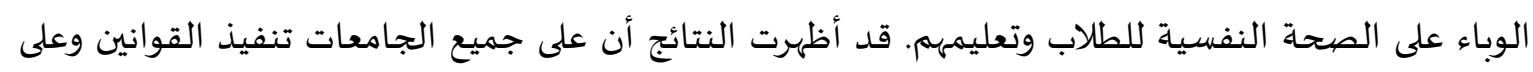

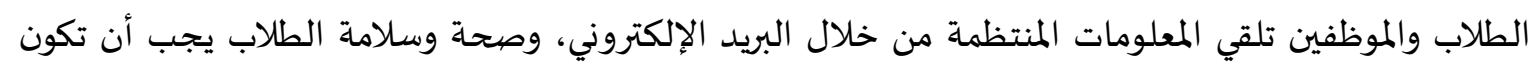

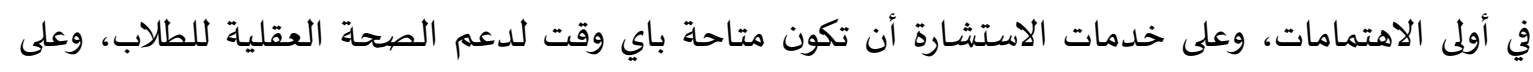


الدولة تحمل مسؤولية السكن والغذاء للطلاب الدوليين، وعلى الهيئة التدريسية الاهتمام بدعم الطلاب لجعل التعليم فعال وغني من الناحية الإلكترونية. دراسـة هينركيسن وآخرون (2020): هدفت الدراسة إلى عرض تصور مقترح لتحويل التعليم من التعليم

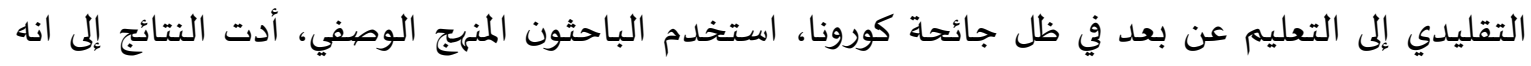

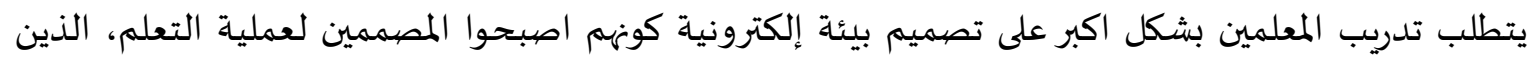

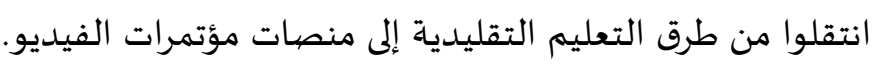
دراسة يو وآخرون:(Yao. J ., et Al, (2020) هدفت الدراسة إلى التعرف إلى الدور الذي يجب أن أن يلعبه المعلمون

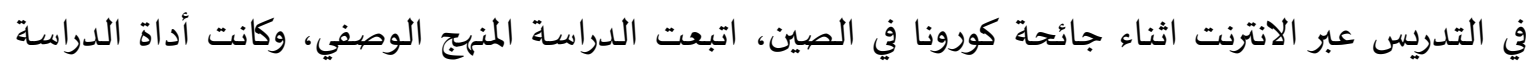

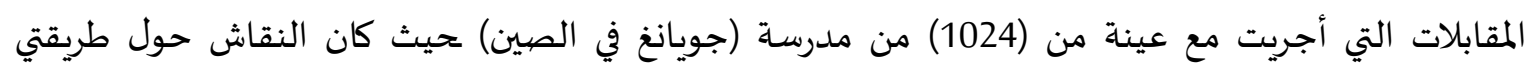

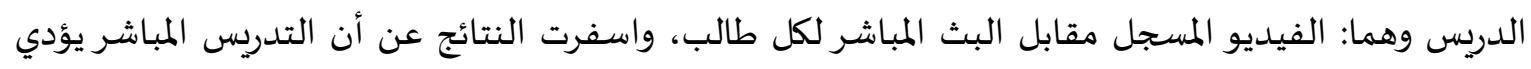
إلى الكثير من التفاعل بين الطلاب والمعلمين ويعتبر الأفضل لتحسين المبل الماداء الاكاديمي للطلاب.

\section{تعقيب على الدراسات السـابقة}

تعقيبا على الدراسات السابقة التي استعرضها الباحثان يتبين أن هذه الدراسات قد تعددت واختلفت

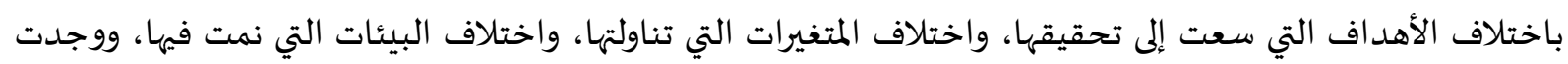

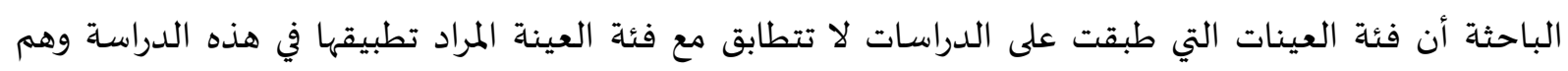

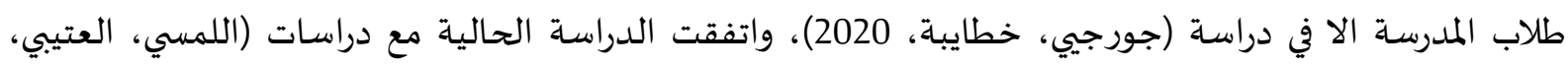
يحياوي، شديفات، قحطاني، 2020) من حيث استخدام المنهج الوصفي، واتفقت أيضا مع دراسات (العتيبي،

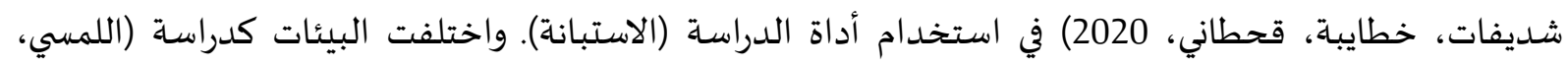

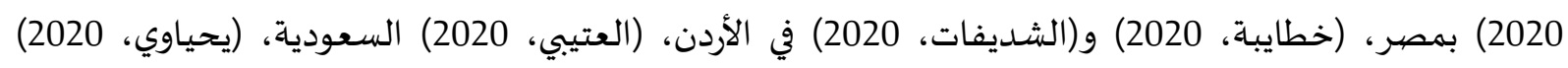

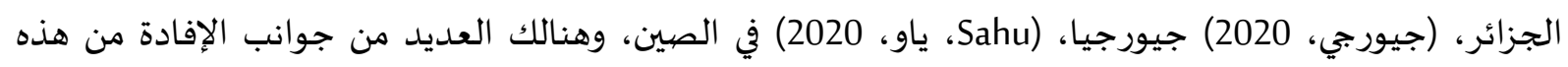

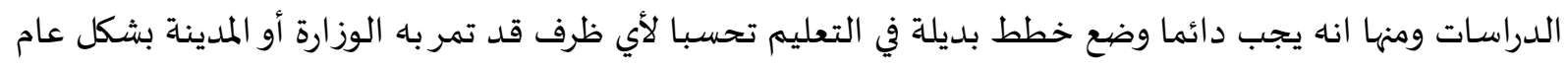

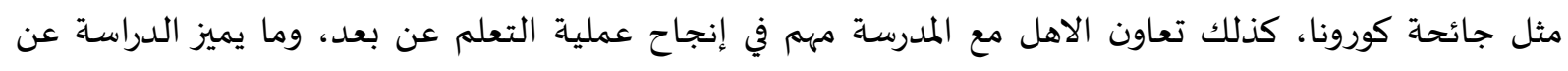

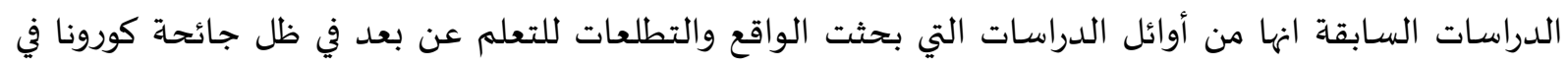

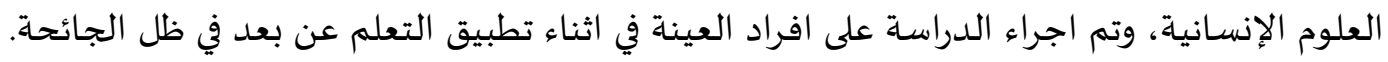

3- منهبية البحث وإجراءاته.

منهجية البحث:

استخدم الباحثان المنهج الوصفي الارتباطي الذي يعتمد على دراسة الظاهرة كما هي في الواقع، ويهتم

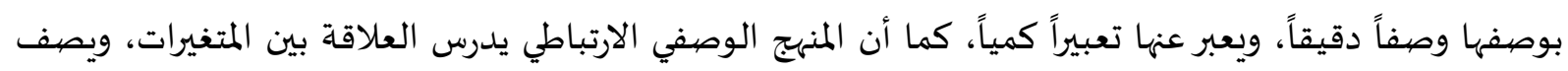

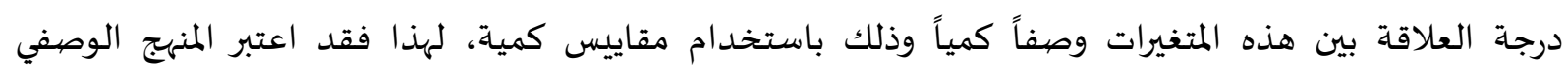

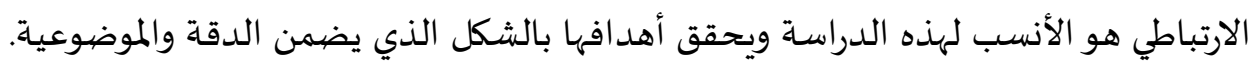


تكون مجتمع الدراسة من طلبة الصف التاسع في العلوم الإنسانية في ظل جائحة كورونا في قرية أبوغوش

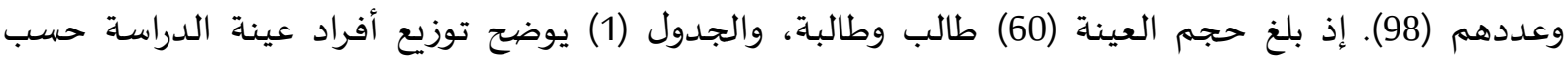

جدول (1): يوضح توزيع أفراد عينة الدراسة حسب متغيرات الدراسة

\begin{tabular}{|c|c|c|c|}
\hline النسبة \% & العدد & الفئات & المتغير \\
\hline 28.3 & 17 & ذكر & \multirow{2}{*}{ الجنس } \\
\hline 71.7 & 43 & أنثى & \\
\hline 73.3 & 44 & ثانوي فما دون & \multirow{4}{*}{ مستوى تعليم الأب } \\
\hline 13.3 & 8 & لقب أول & \\
\hline 10.0 & 6 & ماجستير & \\
\hline 3.3 & 2 & دكتوراه & \\
\hline 50.0 & 30 & ثانوي فما دون & \multirow{4}{*}{ مستوى تعليم الأم } \\
\hline 21.7 & 13 & لقب أول & \\
\hline 25.0 & 15 & ماجستير & \\
\hline 3.3 & 2 & دكتوراه & \\
\hline 56.7 & 34 & تاريخ & \multirow{3}{*}{ المادة الدراسية } \\
\hline 43.3 & 26 & مدنيات & \\
\hline 100.0 & 60 & المجموع & \\
\hline
\end{tabular}

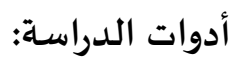

من أجل إنجاز مهام الدراسة وتحقيقاً لأهدافها، طُورت أدوات الدراسة، وذلك بعد الرجوع إلى الأدب

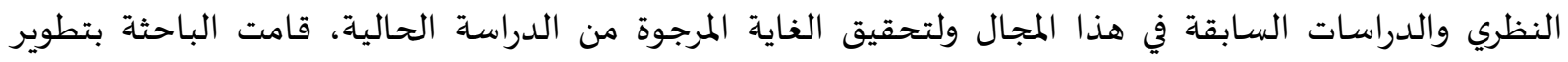

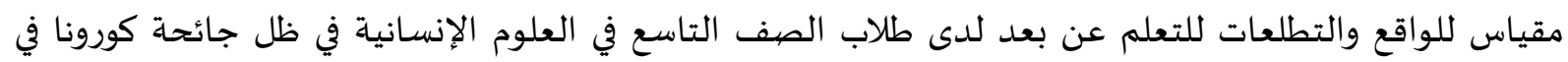
قرية أبو غوش. مقياس لوتع.

صدق الأداة: الصيدق الظاهري (صهدق المحكمين): للتحقق من صدق الاستبانة تم عرضها على الدكتور المشرف الأكاديمي وعلى مجموعة من المحكمين

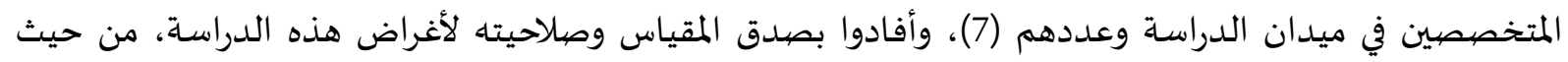

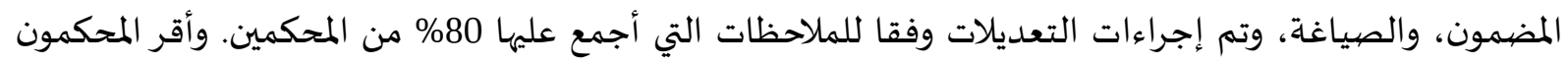

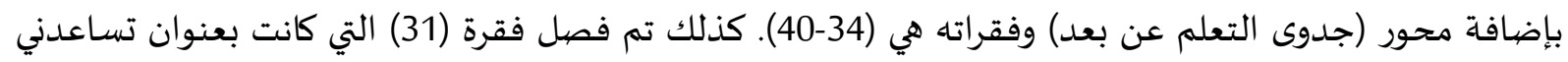

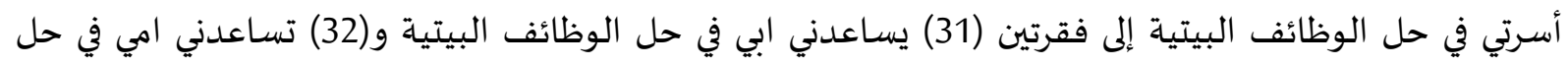

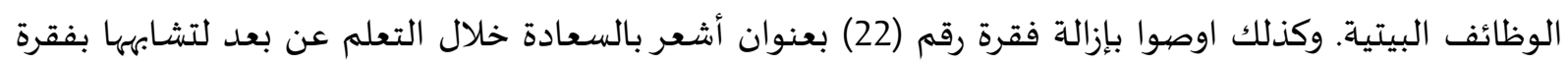

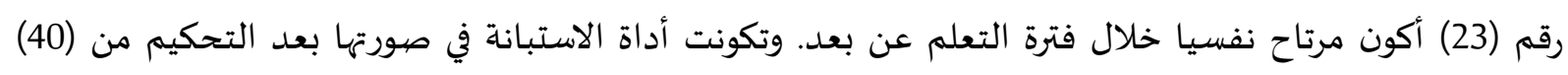

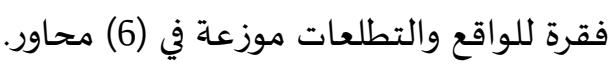




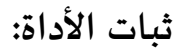

تم التأكد من ثبات الأداة من خلال إجراء اختبار التناسق الداخلي واستخراج معامل الثبات (كرونباخ ألفا)

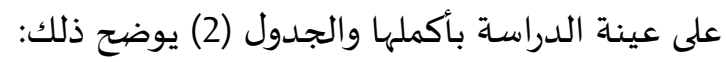
جدول (2): معاملات ثبات مقياس الواقع والتطلعات للتعلم عن بعد لدى طلاب الصفا والدف التاسع في العلوم

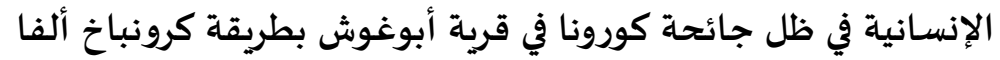

\begin{tabular}{|c|c|c|}
\hline كرونباخ ألفا & عدد الفقرات & البعد \\
\hline 0.948 & 40 & الدرجة الكلية (الواقع) \\
\hline 0.954 & 40 & الدرجة الكلية (التطلعات) \\
\hline
\end{tabular}

يتضح من الجدول (2) أن معامل ثبات كرونباخ ألفا للدرجة الكلية للواقع بلغ (0.948)، فيما بلغ معامل

ثبات كرونباخ ألفا للدرجة الكلية للتطلعات (0.954). وتعتبر هذه القيمة مقبولة عالية الثبات وتجعل من الأدات الثاة قابلة للتطبيق على العينة الأصلية.

\section{المعالجات الإحصائية:}

من أجل معالجة البيانات وبعد جمعها، قامت الباحثة باستخدام برنامج الرزم الإحصائية للعلوم الاجتماعياةSPSS) ) وذلك باستخدام المعالجات الإحصائية الآتية:

$$
\text { 1. }
$$

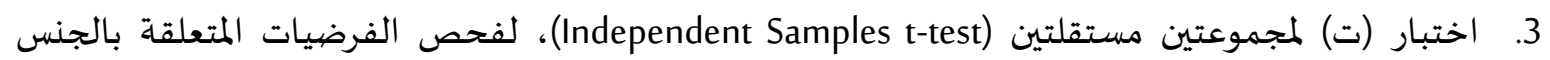

$$
\text { والمستوى التعليمي. }
$$

4. تحليل التباين الأحادي (One-Way ANOVA)، لفحص الفرضيات المتعلقة بمستوى تعليم الأب، مستوى

$$
\text { تعليم الأم. }
$$

$$
\text { (LSD). المقارنات البعدية باستخدام اختبار أقل فرق دال }
$$

6. اختبار بيرسون (Pearson Correlation)لمعرفة العلاقة بين الواقع والتطلعات للتعلم عن بعد لدى لدى طلاب

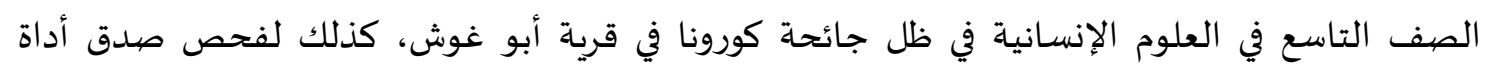

$$
\text { الدارسة. }
$$

\section{4- - 2 - نتائج الدراسـة ومناقشتها.}

النتائج المتعلقة بالسؤال الأول: "ما توجهات طلبة الصف التاسع لواقع التعلم عن بعد في العلوم الإنسانية

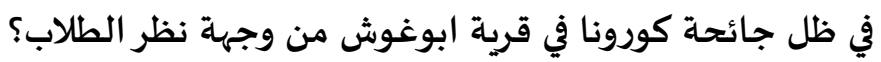

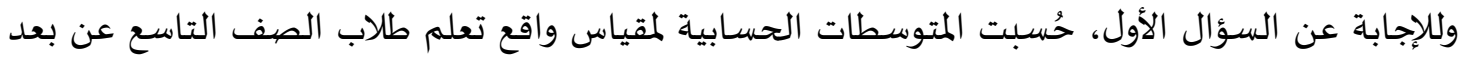

$$
\text { في العلوم الإنسانية في ظل جائحة كورونا في قرية ابوغوش ـ والجدول المول (3) يوضح ذلك: }
$$


جدول (3): المتوسطات الحسابية والانحرافات المعيارية لكل مجال من مجالات واقع تعلم طلاب الصف التاسع

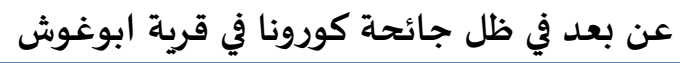

\begin{tabular}{|c|c|c|c|c|c|}
\hline المستوى & النسية & الاندراف & المستوسط & الفقرات & $\hat{\imath}$ \\
\hline مرتفع & 77.8 & 0.75 & 2.33 & تابعت الحصص التعليمية عبر برنامج المشوب خلال فترة التعلم عن بعد. & 1 \\
\hline مرتفع & 79.4 & 0.72 & 2.38 & استخدم جهاز الكتروني (حاسوب) في متابعة الحصص التعليمية عن & 2 \\
\hline مرتفع & 74.4 & 0.81 & 2.23 & استخدم جهاز الهاتف المحمول في متابعة الحصص التعليمية عن بعد. & 3 \\
\hline متوسط & 67.8 & 0.84 & 2.03 & أفضل التعلم التزامني عن طريق برنامج مشوب. & 4 \\
\hline متوسط & 62.8 & 0.78 & 1.88 & أفضل تعلم غير متزامن من خلال مهام محوسبة (مثل الكلاس روم وموقع & 5 \\
\hline متوسط & 67.2 & 0.79 & 2.02 & أفضل تعلم غير متزامن لدروس موثقه بموقع المدرسـة. & 6 \\
\hline مرتفع & 75.6 & 0.76 & 2.27 & تعلمت استخدام الأدوات التكنولوجيا والحوسبة خلال فترة التعليم عن & 7 \\
\hline متوسط & 72.2 & 0.46 & 2.16 & طرق استخدام الأدوات التكنولوجية & \\
\hline مرتفع & 73.9 & 0.69 & 2.22 & معلمو المواد الدراسية متفرغون لي في السـاعات والأيام المحددة في & 8 \\
\hline 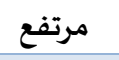 & 81.1 & 0.70 & 2.43 & اتواصل مع طلاب صفي خلال فترة التعلم عن بعد. & 9 \\
\hline متوسط & 73.3 & 0.80 & 2.20 & يتواصل مربي الصف معي في حال أنني لم أشـارك في الحصص التعليمية فترة التعلم عن بعد. & 10 \\
\hline متوسط & 69.4 & 0.79 & 2.08 & يهتمون معلمو المواد بالصعوبات التي أواجهها. & 11 \\
\hline مرتفع & 75.0 & 0.77 & 2.25 & يتابعنا المعلم ويصني لنا أثناء الحصص التعليمية عن بعد. & 12 \\
\hline 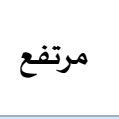 & 73.9 & 0.78 & 2.22 & أسـاعد زملائي الذين لديهم صعوبات في الدخول للحصص التعليمية فلائل فترة التعليم عن بعد. & 13 \\
\hline متوسط & 72.8 & 0.72 & 2.18 & يصغي لي طلاب صفي أثناء مشاركتي بالحصص التعليمية . & 14 \\
\hline 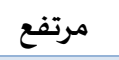 & 74.2 & 0.55 & 2.23 & التواصل بين (الطلاب والمعلم، الطلاب مع بعض) & \\
\hline مرتفع & 75.6 & 0.71 & 2.27 & تمكنت من تعلم مواد جديدة في فترة التعلم عن بعد. & 15 \\
\hline متوسط & 72.2 & 0.83 & 2.17 & أقدم الامتحانات بسهولة ويسر خلال فترة التعلم عن بعد. & 16 \\
\hline مرتفع & 75.6 & 0.76 & 2.27 & أحل وظائفي بسهولة خلال التعلم عن بعد. & 17 \\
\hline متوسط & 63.3 & 0.73 & 1.90 & تتناسب المهام البيتية مع عدد الحصص التعليمية. & 18 \\
\hline متوسط & 61.7 & 0.76 & 1.85 & توجد مصهداقية لنتائج الامتحانات خلال فترة التعلم عن بعد & 19 \\
\hline متوسط & 62.2 & 0.77 & 1.87 & استطيع استيعاب المعلومات بسهولة من خلال الحصص التعليمية & 20 \\
\hline 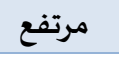 & 77.8 & 0.82 & 2.33 & أسلم وظائفي البيتة دائما بالموعد المححدد. & 21 \\
\hline متوسط & 69.8 & 0.55 & 2.09 & المواد الدراسية والمهام البيتية والامتحانات & \\
\hline متوسط & 62.2 & 0.72 & 1.87 & أكون مرتاح نفسيا خلال فترة التعلم عن بعد. & 22 \\
\hline متوسط & 68.9 & 0.73 & 2.07 & أحب المشـاركة في الحصص التعليمية خلال فترة التعلم عن بعد. & 23 \\
\hline متوسط & 71.7 & 0.86 & 2.15 & تعلمت الالتزام بالحصص التعليمية خلال فترة التعلم عن بعد. & 24 \\
\hline متوسط & 68.9 & 0.84 & 2.07 & تعلمت إدارة الوقت خلال فترة التعلم عن بعد & 25 \\
\hline 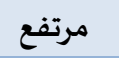 & 82.2 & 0.72 & 2.47 & أشتاق لألعب مع أصهدقائي في فترة التعلم عن بعد. & 26 \\
\hline
\end{tabular}




\begin{tabular}{|c|c|c|c|c|c|}
\hline المستوى & المئوية & الاندراف & المتوسط الحسابي & الفقرات & $\hat{r}$ \\
\hline 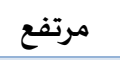 & 77.8 & 0.73 & 2.33 & تعلمت الاستقلالية في العمل خلال فترة التعلم عن بعد. & 27 \\
\hline متوسط & 71.9 & 0.57 & 2.16 & الحالة النفسية للطالب & \\
\hline 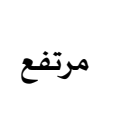 & 77.8 & 0.66 & 2.33 & يوجد جو هادئ ومناسب في المنزل يشجعني على المشاركة في الحصص التعليمية. & 28 \\
\hline مرتفع & 80.0 & 0.72 & 2.40 & تساعدني أسرتي في استعمال المواقع الالكترونية خلل فترة التعلم عن & 29 \\
\hline مرتفع & 87.2 & 0.64 & 2.62 & تهتم أسرتي بمشاركتي في الحصص التعليمية خلال فترة التعلم عن بعد. & 30 \\
\hline متوسط & 63.3 & 0.86 & 1.90 & يساعدني أبي في حل الوظائف البيتية. & 31 \\
\hline متوسط & 73.3 & 0.78 & 2.20 & تساعدني امي في حل الوظائف البيتية. & 32 \\
\hline 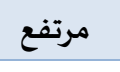 & 78.3 & 0.80 & 2.35 & تتعاون أسرتي مع المعلمين خلال فترة التعليم عن بعد. & 33 \\
\hline 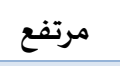 & 76.7 & 0.51 & 2.30 & جاهزية البيئة البيتية وتعاون الاهل & \\
\hline متوسط & 72.2 & 0.76 & 2.17 & أقوم بمراجعة المعلومات التي تعلمتها خلال فترة التعلم عن بعد. & 34 \\
\hline متوسط & 71.1 & 0.72 & 2.13 & استفيد من المعلومات التي اتعلمها خلال فترة التعلم عن بعد. & 35 \\
\hline متوسط & 67.8 & 0.76 & 2.03 & أفهم المواد الدراسية أكثر من خلال التعلم عن بعد. & 36 \\
\hline متوسط & 70.0 & 0.80 & 2.10 & أربط بين المعلومات التي تعلمتها في الحصص التعليمية خلال فترة التعلم & 37 \\
\hline متوسط & 65.6 & 0.86 & 1.97 & أعيد تشغيل الدروس المسجلة في أي وقت عندما أحتاج إلى الرجوع إلى معلومة & 38 \\
\hline متوسط & 69.4 & 0.83 & 2.08 & 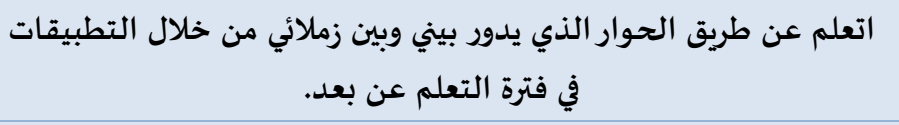 & 39 \\
\hline متوسط & 64.4 & 0.76 & 1.93 & يعطيني التعليم عن بعد دافعية في التعلم. & 40 \\
\hline متوسط & 68.7 & 0.63 & 2.06 & جدوى التعلم عن بعد & \\
\hline متوسط & 72.2 & 0.44 & 2.17 & المتوسط الكلي للمجال & \\
\hline
\end{tabular}

- أظهرت النتائج أن المتوسطات الحسابية لإجابات أفراد عينة الدراسـة على مجال الاتجاهات نحو واقع تعلم

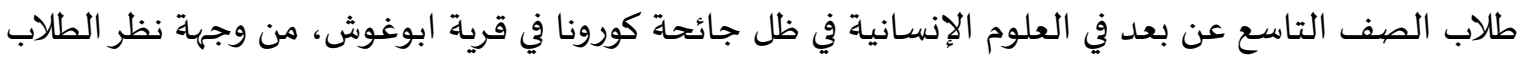
تراوحت ما بين (1.85-2.62 - جاءت فقرة "تهتم أسرتي بمشاركتي في الحصص التعليمية خلال فترة التعلم عن بعد" بالمرتبة الأولى بمتوسط حسابي قدره (2.62) ) وبنسبة مئوية (87.2) وبتقدير مرتفع جدات التدا. جاءت فقرة "توجد مصداقية لنتائج الامتحانات خلال فترة التعلم عن بعد" في المرتبة الأخيرة، بمتوسط حسابي بلغ (1.85) وبنسبة مئوية (61.7) وبتقدير متوسط. قد بلغ المتوسط الحسابي لمجال الواقع نحو تعلم طلاب الصف التاسع عن بعد في العلوم الإنسانية في ظل

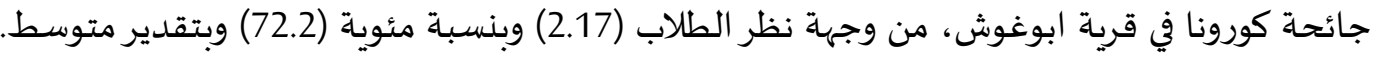


- يعزو الباحثة اهتمام الأهل بتعلم أبنائهم وعدم تعاونهم معهم ومساعدتهم في حل الوظائف، لجهلهم في معرفة

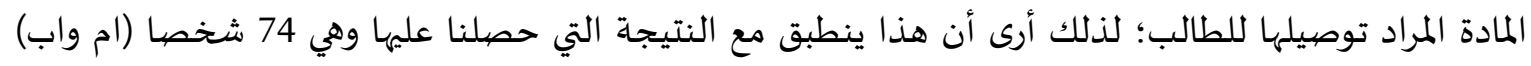

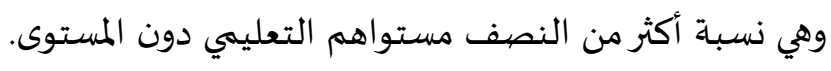

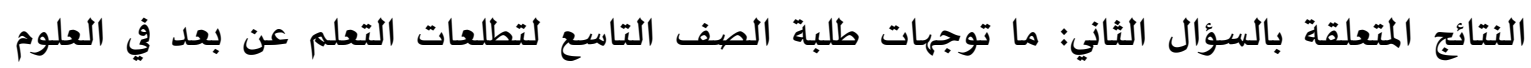

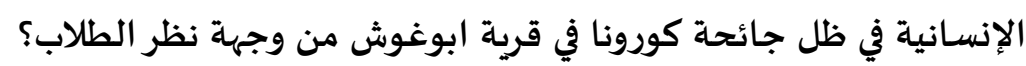

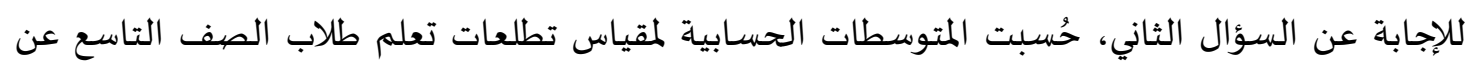

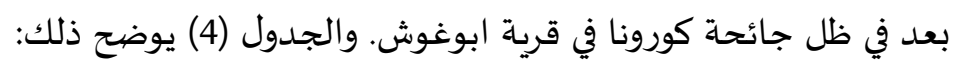

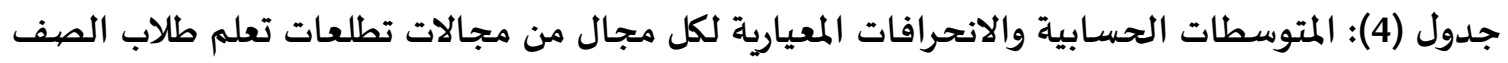

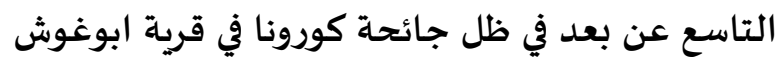

\begin{tabular}{|c|c|c|c|c|c|}
\hline المستوى & النسبة & الانحراف & المتوسـط التحسبابي & الفقرات & $\hat{\imath}$ \\
\hline 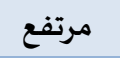 & 77.2 & 0.75 & 2.32 & تابعت الحصص التعليمية عبر برنامج المشوب خلال فترة التعلم عن بعد. & 1 \\
\hline مرتفع & 80.0 & 0.69 & 2.40 & استخدم جهاز الكتروني (حاسوب) في متابعة الحصص التعليمية عن بعد. & 2 \\
\hline مرتفع & 74.4 & 0.81 & 2.23 & استخدم جهاز الهاتف المحمول في متابعة الحصص التعليمية عن بعد. & 3 \\
\hline متوسط & 66.1 & 0.83 & 1.98 & أفضل التعلم التزامني عن طريق برنامج مشوب. & 4 \\
\hline متوسط & 66.7 & 0.74 & 2.00 & أفضل تعلم غير متزامن من خلال مهام محوسبة (مثل الكلاس روم وموقع & 5 \\
\hline متوسط & 67.8 & 0.76 & 2.03 & أفضل تعلم غير متزامن لدروس موثقه بموقع المدرسـة. & 6 \\
\hline مرتفع & 77.8 & 0.75 & 2.33 & تعلمت استخدام الأدوات التكنولوجيا والحوسبة خلال فترة التعليم عن & 7 \\
\hline متوسط & 72.9 & 0.48 & 2.19 & طرق استخـدام الأدوات التكنولوجية & \\
\hline 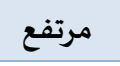 & 78.3 & 0.66 & 2.35 & معلمو المواد الدراسية متفرغين لي في السـاعات والأيام المحددة في البرنامج. & 8 \\
\hline 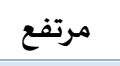 & 77.2 & 0.75 & 2.32 & اتواصل مع طلاب صفي خلال فترة التعلم عن بعد. & 9 \\
\hline مرتفع & 78.3 & 0.76 & 2.35 & يتواصل مربي الصف معي في حال أنني لم أشـارك في الحصص التعليمية فترة التعلم عن بعد. & 10 \\
\hline متوسط & 71.1 & 0.79 & 2.13 & يهتمون معلمو المواد بالصعوبات التي أواجهها. & 11 \\
\hline 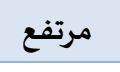 & 78.9 & 0.69 & 2.37 & يتابعنا المعلم ويصغي لنا أثناء الحصص التعليمية عن بعد. & 12 \\
\hline مرتفع & 77.2 & 0.75 & 2.32 & أسـاعد زملائي الذين لديهم صعوبات في الدخول للحصص التعليمية خلال & 13 \\
\hline متوسط & 73.3 & 0.68 & 2.20 & يصغي لي طلاب صفي أثناء مشـاركتي بالحصص التعليمية . & 14 \\
\hline 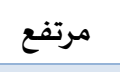 & 76.3 & 0.54 & 2.29 & التواصل بين (الطلاب والمعلم، الطلاب مع بعض) & \\
\hline مرتفع & 73.9 & 0.76 & 2.22 & تمكنت من تعلم مواد جديدة في فترة التعلم عن بعد. & 15 \\
\hline متوسط & 72.2 & 0.76 & 2.17 & أقدم الامتحانات بسهولة ويسر خلال فترة التعلم عن بعد. & 16 \\
\hline 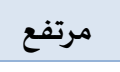 & 76.7 & 0.81 & 2.30 & أحل وظائفي بسهولة خلال التعلم عن بعد. & 17 \\
\hline متوسط & 68.9 & 0.76 & 2.07 & تتناسب المهام البيتية مع عدد الحصص التعليمية. & 18 \\
\hline متوسط & 63.9 & 0.77 & 1.92 & توجد مصيداقية لنتائج الامتحانات خلال فترة التعلم عن بعد & 19 \\
\hline
\end{tabular}




\begin{tabular}{|c|c|c|c|c|c|}
\hline المستوى & المنيبة & الانحراف & المتوسط الحسبابي & الفقرات & $\hat{\imath}$ \\
\hline متوسط & 65.0 & 0.75 & 1.95 & استطيع استيعاب المعلومات بسهولة من خلال الحصص التعليمية & 20 \\
\hline مرتفع & 81.1 & 0.74 & 2.43 & أسلم وظائفي البيتة دائما بالموعد المحددد. & 21 \\
\hline متوسط & 71.7 & 0.60 & 2.15 & المواد الدراسية والمهام البيتية والامتححانات & \\
\hline متوسط & 66.1 & 0.77 & 1.98 & أكون مرتاح نفسيا خلال فترة التعلم عن بعد. & 22 \\
\hline متوسط & 72.2 & 0.81 & 2.17 & أحب المشـاركة في الحصص التعليمية خلال فترة التعلم عن بعد. & 23 \\
\hline مرتفع & 75.0 & 0.79 & 2.25 & تعلمت الالتزام بالحصص التعليمية خلال فترة التعلم عن بعد. & 24 \\
\hline 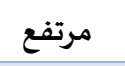 & 76.7 & 0.74 & 2.30 & تعلمت إدارة الوقت خلال فترة التعلم عن بعد & 25 \\
\hline مرتفع & 85.6 & 0.67 & 2.57 & أشتاق لألعب مع أصدقائي في فترة التعلم عن بعد. & 26 \\
\hline مرتفع & 78.3 & 0.73 & 2.35 & تعلمت الاستقلالية في العمل خلال فترة التعلم عن بعد. & 27 \\
\hline 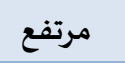 & 75.7 & 0.57 & 2.27 & 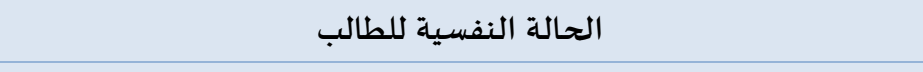 & \\
\hline مرتفع & 83.3 & 0.68 & 2.50 & يوجد جو هادئ ومناسب في المنزل يشجعني على المشاركة في الحصص التعليمية. & 28 \\
\hline مرتفع & 83.9 & 0.68 & 2.52 & تسـاعدني أسرتي في استعمال المواقع الالكترونية خلل فترة التعلم عن بعد. & 29 \\
\hline 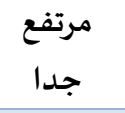 & 87.2 & 0.67 & 2.62 & تهتم أسرتي بمشاركتي في الحصص التعليمية خلال فترة التعلم عن بعد. & 30 \\
\hline متوسط & 66.7 & 0.90 & 2.00 & يساعدني أبي في حل الوظائف البيتية. & 31 \\
\hline 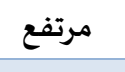 & 77.2 & 0.77 & 2.32 & تسـاعدني امي في حل الوظائف البيتية. & 32 \\
\hline مرتفع & 80.0 & 0.79 & 2.40 & تتعاون أسرتي مع المعلمين خلال فترة التعليم عن بعد. & 33 \\
\hline 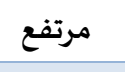 & 79.7 & 0.55 & 2.39 & جاهزية البيئة البيتية وتعاون الاهل & \\
\hline مرتفع & 75.6 & 0.76 & 2.27 & أقوم بمراجعة المعلومات التي تعلمتها خلال فترة التعلم عن بعد. & 34 \\
\hline متوسط & 70.6 & 0.78 & 2.12 & استفيد من المعلومات التي اتعلمها خلال فترة التعلم عن بعد. & 35 \\
\hline متوسط & 68.3 & 0.79 & 2.05 & أفهم المواد الدراسية أكثر من خلال التعلم عن بعد. & 36 \\
\hline متوسط & 73.3 & 0.78 & 2.20 & أربط بين المعلومات التي تعلمتها في الحصص التعليمية خلال فترة التعلم & 37 \\
\hline متوسط & 70.0 & 0.82 & 2.10 & أعيد تشغيل الدروس المسجلة في أي وقت عندما أحتاج إلى الرجوع إلى أي & 38 \\
\hline مرتفع & 76.1 & 0.76 & 2.28 & اتعلم عن طريق الحوار الذي يدور بيني وبين زملائي من خلال التطبيقات في & 39 \\
\hline متوسط & 69.4 & 0.77 & 2.08 & يعطيني التعليم عن بعد دافعية في التعلم. & 40 \\
\hline متوسط & 71.9 & 0.64 & 2.16 & جدوى التعلم عن بعد & \\
\hline مرتفع & 74.7 & 0.45 & 2.24 & المتوسط الكلي للمجال & \\
\hline
\end{tabular}

أظهرت النتائج أن المتوسطات الحسابية لإجابات أفراد عينة الدراسة على مجال الاتجاهات نحو تطلعات تعلم طلاب الصف التاسع عن بعد في ظل جائحة كورونا في قرية ابوغوش تراوحت ما بين (2.62-1.92) 
جاءت فقرة "هتتم أسرتي بمشاركتي في الحصص التعليمية خلال فترة التعلم عن بعد" بالمرتبة الأولى بمتوسط حسابي قدرة (2.62) وبنسبة مئوية (87.2) وبتقدير مرتفع جداء جاءت فقرة "توجد مصداقية لنتائج الامتحانات خلال فترة التعلم عن بعد" في المرتبة الأخيرة، بمتوسط حسابي بلغ (1.92) وبنسبة مئوية (63.9) وبتقدير متوسط، قد بلغ المتوسط الحسابي لمجال التطلعات نحو التعلم (2.24) وبنسبة مئوية (74.7) وبتقدير مرتفع. يعزو الباحثان هذه النتيجة إلى عدم قدرة الطلاب في تقييم الوضع الجديد عليهم، الذي جاء بشكل مفاجئ

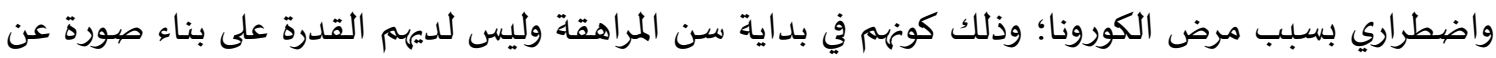
المستقبل وتطلعاتهم غير بعيدة المدى، حيث انهم لا يرون الا ما يخدم مصليلحتههم الانية.

النتائج المتعلقة بالفرضيات

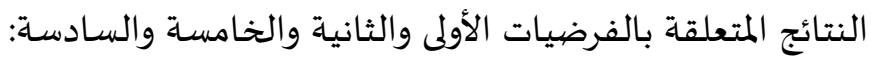
ومن أجل فحص الفرضيات وتحديد الفروق تبعاً لمتغير الجنس والمادة الدراسية، استخدلة والفية اختبار (ت) لمجموعتين مستقلتين (Independent Samples t-test).

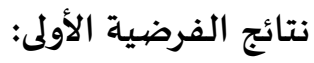
الجدول (5): نتائج اختبار (ت) لدلالة الفروق بين متوسطات استجابات عينة الدارسة لواقع التعلم عن بعد في

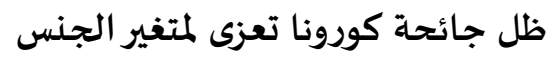

\begin{tabular}{|c|c|c|c|c|c|c|}
\hline مستوى الدلالة & قيمة (ت) & الانحراف & المتوسط & العدد & الجنس & المجالات \\
\hline \multirow[t]{2}{*}{865.} & 170.- & .40913 & 2.1513 & 17 & ذكر & \multirow{2}{*}{ الدرجة الكلية } \\
\hline & & .45783 & 2.1730 & 43 & أنثى & \\
\hline
\end{tabular}

يتبين من الجدول (5): أن قيمة مستوى الدلالة المحسوب على الدرجة الكلية لواقع التعلم عن بعد في ظل

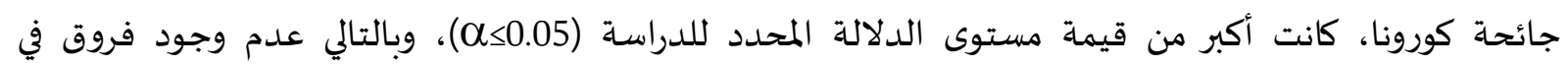
استجابات عينة الدارسة لواقع التعلم عن بعد في ظل جائحة كورونا تعزى لمتغير الجنس.

نتائج الفرضية الثانية: الجدول (6): يوضح نتائج اختبار (ت) لدلالة الفروق بين متوسطات استجابات عينة الدارسة لواقع التعلم عن

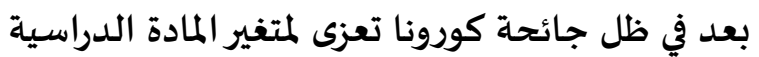

\begin{tabular}{|c|c|c|c|c|c|c|}
\hline مستوى الدلالة & قيمة (ت) & الانحراف & المتوسط & 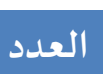 & المادة الدراسية & المجالات \\
\hline \multirow[t]{2}{*}{776.} & 286.- & .46572 & 2.1525 & 34 & تاريخ & \multirow{2}{*}{ الدرجة الكلية } \\
\hline & & .41538 & 2.1856 & 26 & مدنيات & \\
\hline
\end{tabular}

يتبين من الجدول (6): أن قيمة مستوى الدلالة المحسوب على الدرجة الكلية لواقع التعلم عن بعد في ظل

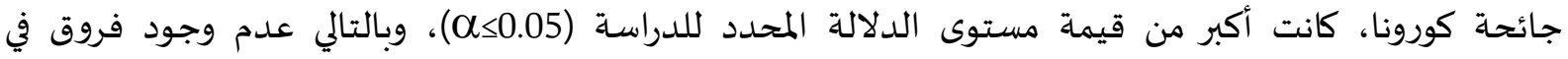
استجابات عينة الدارسة لواقع التعلم عن بعد في ظل جائحة كورونا تعزى لمتغير المادة الدراسية. 
الجدول (7): يوضح نتائج اختبار (ت) لدلالة الفروق بين متوسطات استجابات عينة الدارسة لتطلعات التعلم

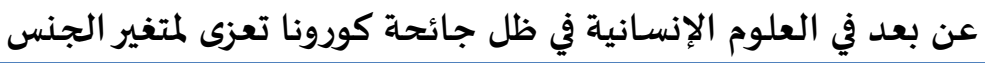

\begin{tabular}{|c|c|c|c|c|c|c|}
\hline مستوى الدلالة & قيمة (ت) & الانحراف & المتوسط & العدد & الجنس & المجالات \\
\hline \multirow[t]{2}{*}{442.} & 774. & .42942 & 2.3125 & 17 & ذكر & \multirow{2}{*}{ الدرجة الكلية } \\
\hline & & .46096 & 2.2122 & 43 & أنثى & \\
\hline
\end{tabular}

يتبين من الجدول (7): أن قيمة مستوى الدلالة المحسوب على الدرجة الكلية لتطلعات التعلم عن بعد في

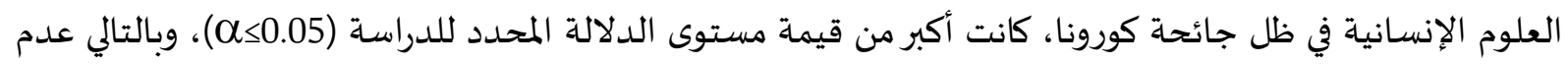
وجود فروق في استجابات عينة الدارسة لتطلعات التعلم عن بعد في العلوم الإنسانية في ظل جائحة كورونا تعزى الإنى لمتنير الجنس.

نتائج الفرضية السادسـة: الجدول (8): يوضح نتائج اختبار (ت) لدلالة الفروق بين متوسطات استجابات عينة الدارسة لتطلعات التعلم

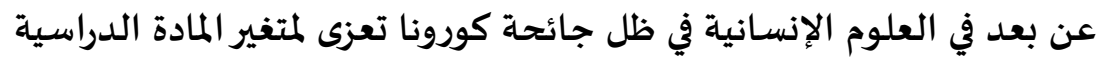

\begin{tabular}{|c|c|c|c|c|c|c|}
\hline مستوى الدلالة & قيمة (ت) & الانحراف & المتوسط & العدد & المادة الدراسية & المجالات \\
\hline \multirow[t]{2}{*}{732.} & 344.- & .47604 & 2.2230 & 34 & تاريخ & \multirow{2}{*}{ الدرجة الكلية } \\
\hline & & .42401 & 2.2637 & 26 & مدنيات & \\
\hline
\end{tabular}

يتبين من الجدول (8): أن قيمة مستوى الدلالة المحسوب على الدرجة الكلية لتطلعات التعلم عن بعد في

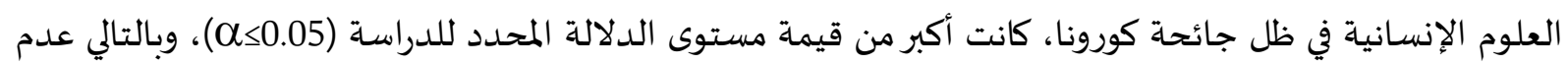

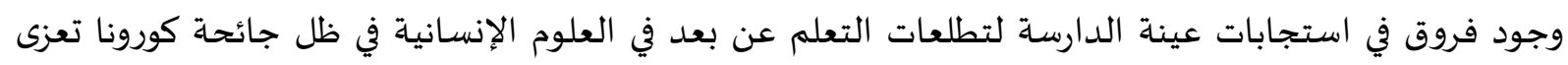

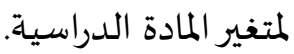
أظهرت النتائج أن قيمة مستوى الدلالة المحسوب على الدرجة الكلية لواقع وتطلعات التعلم عن بعد في

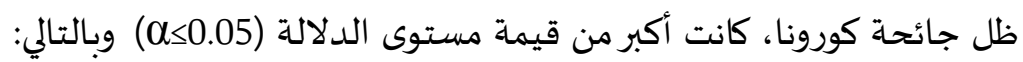

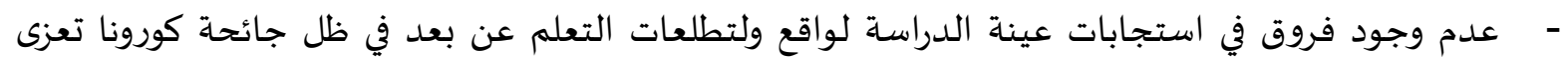

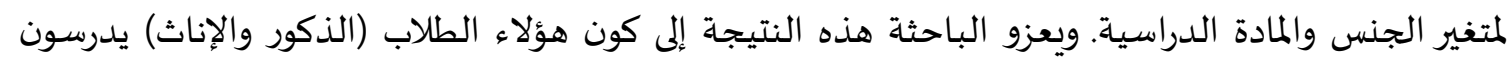
سويا منذ مراحلهم الأساسية في نفس المدرسة (ابوغوش)، فهم متأثرون بنفس البيئة التعليمية التربوي.

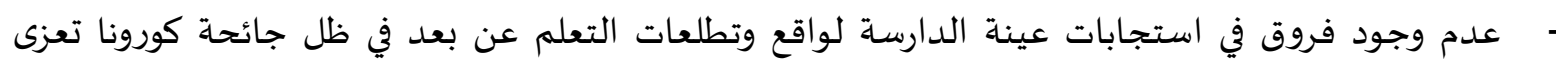
المتغير المادة الدراسية.

النتائج المتعلقة بالفرضيات الثالثة والرابعة والسابعة والثامنة : ومن أجل فحص الفرضيات، استخرجت المتوسطات الحسابية والانحرافات المعيارية تبعاً لمتغير مستوى

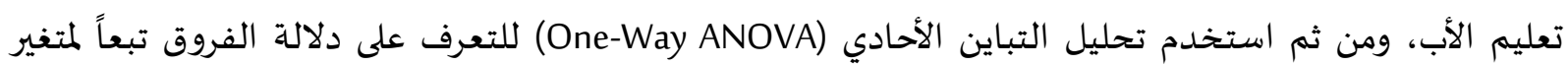
مستوى تعليم الأب والأم. 
نتائج الفرضية الثالثة: جدول (9): يوضح المتوسطات الحسابية والانحرافات المعيارية لمتوسطات استجابات عينة الدارسة لواقع التعلم عن بعد في العلوم الإنسانية في ظل جائحة كورونا تعزى لمتغير مستوى تعليم الأب.

\begin{tabular}{|c|c|c|c|c|}
\hline الانحراف المعياري & المتوسط الحسابي & 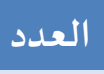 & مستوى تعليم الأب & المجال \\
\hline .47276 & 2.1332 & 44 & ثانوي فما دون & \multirow{4}{*}{ الدرجة الكلية } \\
\hline .24176 & 2.2683 & 8 & لقب أول & \\
\hline .39599 & 2.2094 & 6 & ماجستير & \\
\hline .67529 & 2.3725 & 2 & دكتور اه & \\
\hline
\end{tabular}

يتضح من خلال الجدول (9) وجود فروق بين المتوسطات الحسابية، ومن أجل معرفة إن كانت هذه

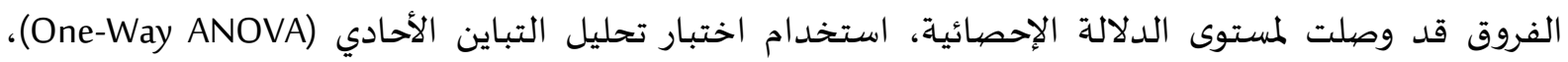
والجدول (10)يوضح ذلك: جدول (10): نتائج تحليل التباين الأحادي على الدرجة الكلية لمتوسطات استجابات عينة الدارسة لواقع التعلم

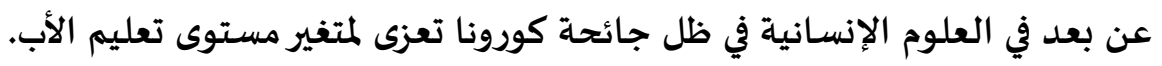

\begin{tabular}{|c|c|c|c|c|c|c|}
\hline مستوى الدلالة & المحسوبة & متوسط المربعات & درجات & المربعات متموع & مصيدر التباين & \\
\hline \multirow[t]{3}{*}{.770} & .377 & .076 & 3 & .228 & بين المجموعات & \multirow{3}{*}{ الدرجة الكلية } \\
\hline & & .201 & 56 & 11.260 & داخل المجموعات & \\
\hline & & & 59 & 11.487 & المجموع & \\
\hline
\end{tabular}

يتبين من الجدول (10): أن قيمة مستوى الدلالة المحسبوب على الدرجة الكلية لواقع التعلم عن بعد في ظل

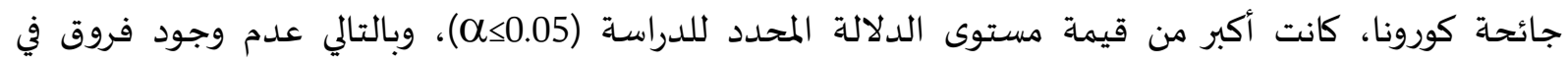
استجابات عينة الدارسة لواقع التعلم عن بعد في العلوم الانسانية في ظل جائحة كورونا تعزى لمتغير مستوى تعليم

نتائج الفرضية الرابعة: جدول (11): المتوسطات الحسابية والانحرافات المعيارية لمتوسطات استجابات عينة الدارسة لواقع التعلم عن بعد في العلوم الإنسانية في ظل جائحة كورونا تعزى لمتغير مستوى تعليم المتيمات الأم.

\begin{tabular}{|c|c|c|c|c|}
\hline الانحراف المعياري & المتوسط الحسابي & 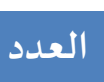 & مستوى تعليم الأم & المجال \\
\hline .46233 & 2.2271 & 30 & ثانوي فما دون & \multirow{4}{*}{ الدرجة الكلية } \\
\hline .44053 & 2.1859 & 13 & لقب أول & \\
\hline .42663 & 2.0389 & 15 & ماجستير & \\
\hline .20742 & 2.0983 & 2 & دكتوراه & \\
\hline
\end{tabular}

يتضح من خلال الجدول (11) وجود فروق بين المتوسطات الحسابية، ومن أجل معرفة إن كانت هذه

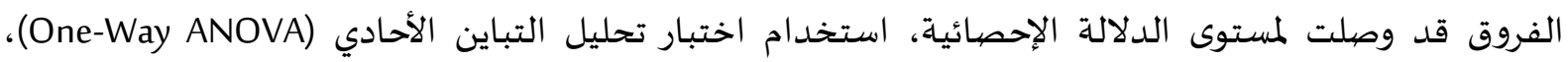
والجدول (12) يوضح ذلك: 
جدول (12): يوضيح نتائج تحليل التباين الأحادي على الدرجة الكلية لمتوسطات استجابات عينة الدارسة لواقع التعلم عن بعد في العلوم الإنسانية في ظل جائحة كورونا تعزى لمتغير مستوى تعليم الأم.

\begin{tabular}{|c|c|c|c|c|c|c|}
\hline مستوى الدلالة & "المحسوبة & متوسط المربعات & درجات & المربعات & مصدر التباين & \\
\hline \multirow[t]{3}{*}{.606} & .619 & .123 & 3 & .369 & بين المجموعات & \multirow{3}{*}{ الدرجة الكلية } \\
\hline & & .199 & 56 & 11.119 & داخل المجموعات & \\
\hline & & & 59 & 11.487 & المجموع & \\
\hline
\end{tabular}

يتبين من الجدول (12): أن قيمة مستوى الدلالة المحسوب على الدرجة الكلية لواقع التعلم عن بعد في

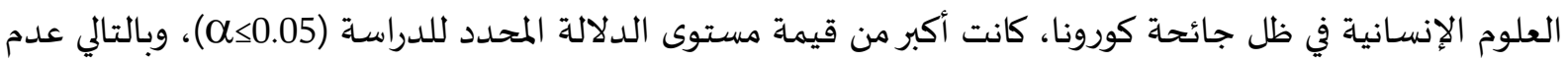
وجود فروق في استجابات عينة الدارسة لواقع التعلم عن بعد في العلوم الإنسانية في ظل جائحة كورونا تعزى لمتغير مستوى تعليم الأم. أظهرت النتائج أن قيمة مستوى الدلالة المحسوب على الدرجة الكلية لواقع وتطلعات التعلم عن بعد في

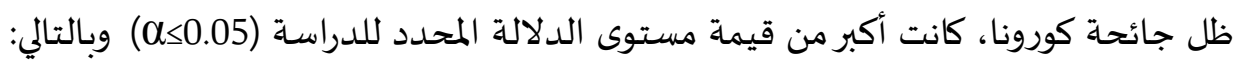
عدم وجود فروق في استجابات عينة الدارسة لواقع وتطلعات التعلم عن بعد في العلوم الإنسانية في ظل جائحة كورونا تعزى لمتغير مستوى تعليم الأب والأم..

نتائج الفرضية السـابعة: جدول (13): يوضح المتوسطات الحسابية والانحرافات المعيارية لمتوسطات استجابات عينة الدارسـة لتطلعات التعلم عن بعد في العلوم الإنسانية في ظل جائحة كورونا تعزى لمتغير مستوى تعليم الأب.

\begin{tabular}{|c|c|c|c|c|}
\hline الانحراف المعياري & المتوسط الحسابي & العدد العد & مستوى تعليم الأب & المجال \\
\hline .49352 & 2.2417 & 44 & ثانوي فما دون & \multirow{4}{*}{ الدرجة الكلية } \\
\hline .23962 & 2.2481 & 8 & لقب أول & \\
\hline .36594 & 2.1519 & 6 & ماجستير & \\
\hline .56097 & 2.4533 & 2 & دكتوراه & \\
\hline
\end{tabular}

يتضح من خلال الجدول (13): وجود فروق بين المتوسطات الحسابية، ومن أجل معرفة إن كانت هذه الفروق قد وصلت لمستوى الدلالة الإحصائية، استخدام اختبار تحليل التباين الأحادي (One-Way ANOVA)، والجدول (14) يوضح ذلك:

جدول (14): يوضح نتائج تحليل التباين الأحادي على الدرجة الكلية لمتوسطات استجابات عينة الدارسة لتطلعات التعلم عن بعد في العلوم الإنسانية في ظل جائحة كورونا تعزى لمتغير مستوى تعليم الأب.

\begin{tabular}{|c|c|c|c|c|c|c|}
\hline الدلالة مستوى & "لمسيوبة & متوسط المربعات & درجات & المربعات & مصيدر التباين & \\
\hline \multirow[t]{3}{*}{.884} & .217 & .046 & 3 & .138 & بين المجموعات & \multirow{3}{*}{ الدرجة الكلية } \\
\hline & & .212 & 56 & 11.859 & داخل المجموعات & \\
\hline & & & 59 & 11.997 & المجموع & \\
\hline
\end{tabular}


يتبين من الجدول (14): أن قيمة مستوى الدلالة المحسوب على الدرجة الكلية لتطلعات التعلم عن بعد في

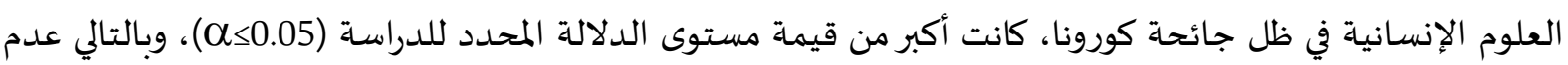
وجود فروق في استجابات عينة الدارسة نحو لتطلعات التعلم عن بعد في العلوم الإنسانية في ظل جائحة كورونا تعزى لمتغير مستوى تعليم الأب.

نتائج الفرضية الثامنة: ومن أجل فحص الفرضية الثامنة، استخرجت المتوسطات الحسابية والانحرافات المعيارية تبعاً لمتغير مستوى تعليم الأم، ومن ثم استخدم تحليل التباين الأحادي (One-Way ANOVA) للتعرف على دلى دلالة الفروق تبعاً

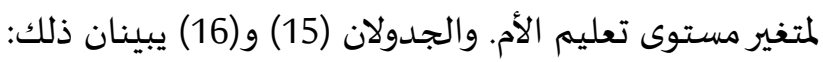

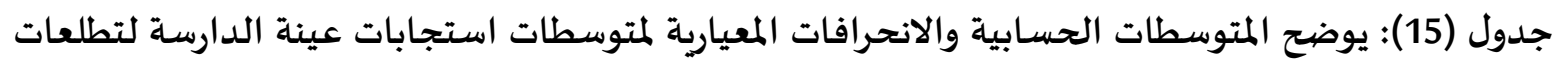
التعلم عن بعد في العلوم الإنسانية في ظل جائحة كورونا تعزى لمتغير مستوى تعليم الأم.

\begin{tabular}{|c|c|c|c|c|}
\hline الانحراف المعياري & المتوسط الحسابي & العدد العد & مستوى تعليم الأم & المجال \\
\hline .47980 & 2.2646 & 30 & ثانوي فما دون & \multirow{4}{*}{ الدرجة الكلية } \\
\hline .46918 & 2.1835 & 13 & لقب أول & \\
\hline .42507 & 2.2629 & 15 & ماجستير & \\
\hline 18856 & 2.0867 & 2 & دكتوراه & \\
\hline
\end{tabular}

يتضح من خلال الجدول (15) وجود فروق بين المتوسطات الحسابية، ومن أجل معرفة إن كانت هذه

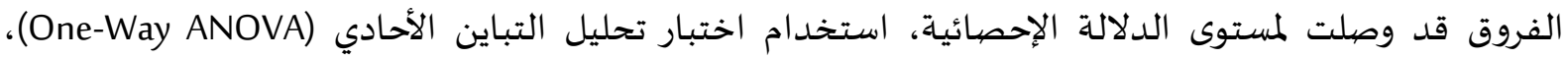
والجدول (16)يوضح ذلك:

جدول (16): يوضح نتائج تحليل التباين الأحادي على الدرجة الكلية لمتوسطات استجابات عينة الدارسة

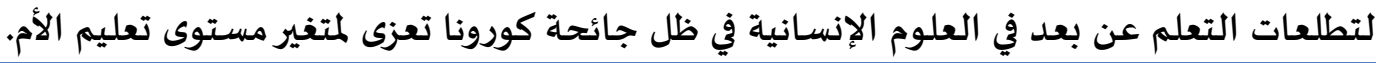

\begin{tabular}{|c|c|c|c|c|c|c|}
\hline مستوى الدلالة & المحسوبة & متوسط المربعات & درجات & المربعات متموع & مصدر التباين & \\
\hline \multirow[t]{3}{*}{.910} & .180 & .038 & 3 & .115 & بين المجموعات & \multirow{3}{*}{ الدرجة الكلية } \\
\hline & & .212 & 56 & 11.883 & داخل المجموعات & \\
\hline & & & 59 & 11.997 & المجموع & \\
\hline
\end{tabular}

يتبين من الجدول (16) أن قيمة مستوى الدلالة المحسوب على الدرجة الكلية لتطلعات التعلم عن بعد في

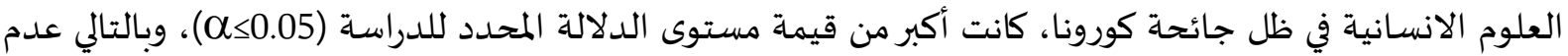
وجود فروق في استجابات عينة الدارسة لتطلعات التعلم عن بعد في العلوم الإنسانية في ظل جائحة كورونا تعزى

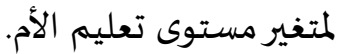


نتائج الفرضية التاسعة:

ومن أجل فحص الفرضية التاسعة، استخرجت معامل ارتباط بيرسون، ومن ثم استخدمت تحليل الارتباط

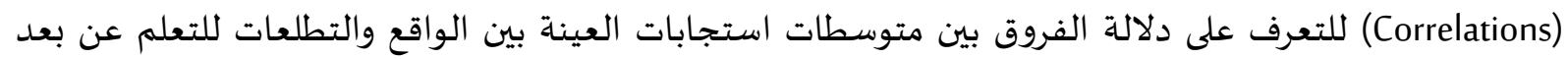

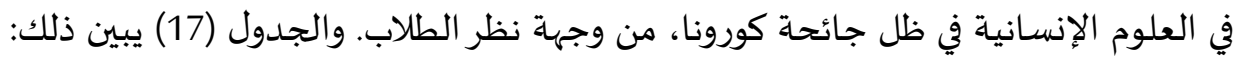

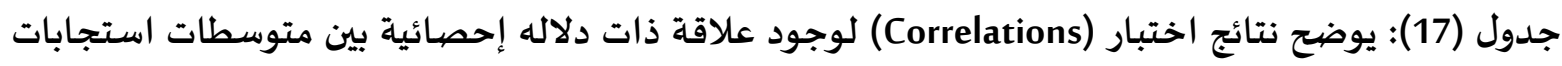

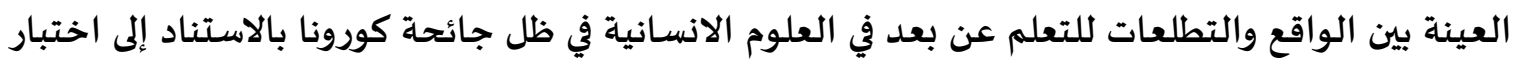

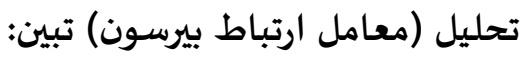

\begin{tabular}{|c|c|c|}
\hline التعليم عن بعد & & \\
\hline $.838^{* *} 0$ & معامل ارتباط بيرسون & \multirow{3}{*}{ التطلعات للتعلم عن بعد } \\
\hline 0.000 & مستوى الدلالة & \\
\hline 60 & 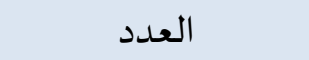 & \\
\hline
\end{tabular}

أن قيمة مستوى الدلالة أصغر من 0.05 وهي بذلك دالة إحصائيا، لذا فإننا نرفض الفرضية الصفرية القائلة

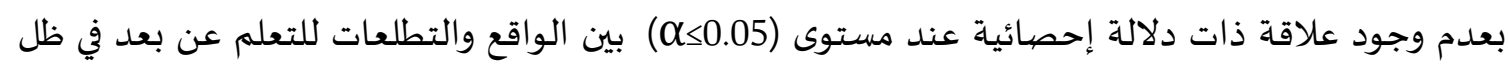
جائحة كورونا. نقبل الفرضية البديلة القائلة بوجود علاقة ذات دلالة إحصائية عند مستوى (0.05) مبين الواقع والتطلعات للتعلم عن بعد في ظل جائحة كورونا. بالاستناد إلى اختبار تحليل معامل ارتباط بيرسون والذي قيمته 0.838 وهي قيمة قوية وفي نفس الوقت الأمر

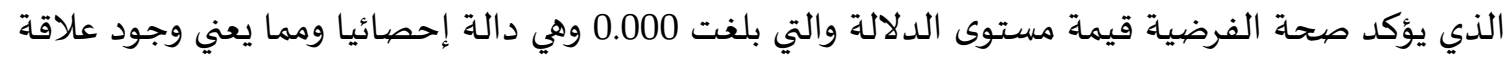

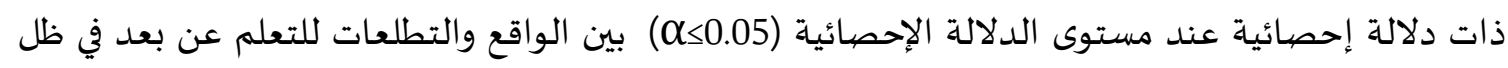
جائحة كورونا. ويعزو الباحثان هذه النتيجة إلى عدم قدرة الطلاب في تقييم الوضع الجديد علههم، الذي جاء بشكل مفاجئ

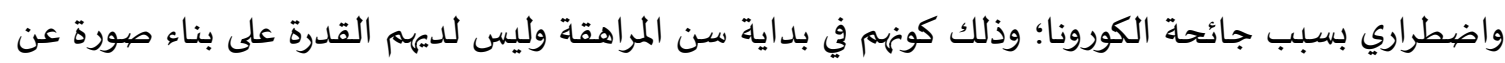

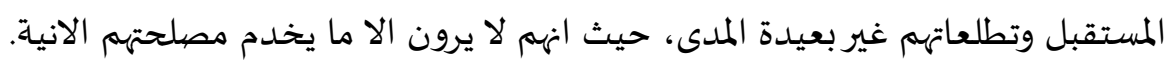

مناقشـة النتائج: اتفقت نتائج الدراسة مع نتائج دراسات (خطايبة وآخرون، 2020)، ويعزو الباحثان ذلك إلى عدم جهوزية

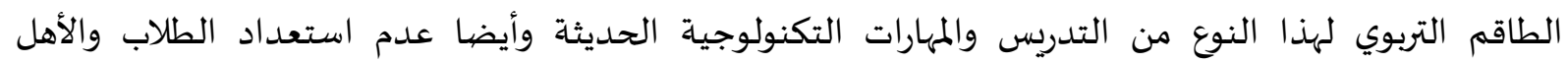

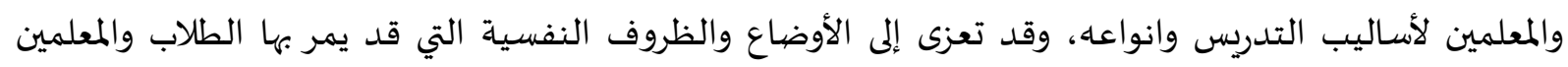

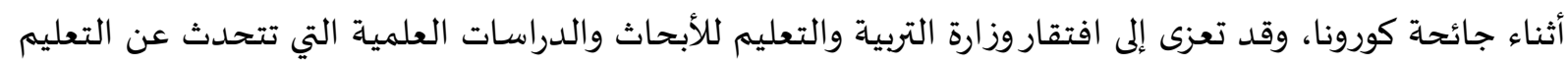

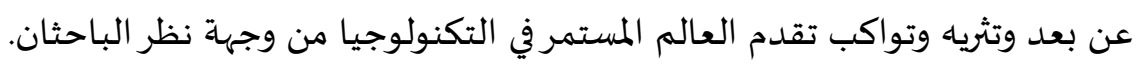

التوصيات والمقترحات. في ضوء نتائج الدراسة السابقة يوصي الباحثان بما يلي: 
1- التوصية الخاصة بالسؤال الأول: يوصي الباحثان بتشجيع ومساعدة الاهل لأبنائهم في توفير وسائط تعليمية

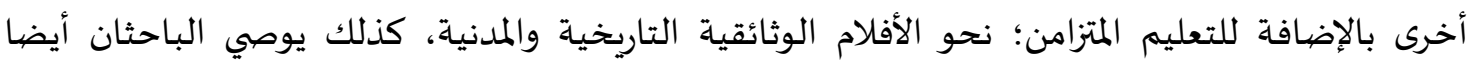

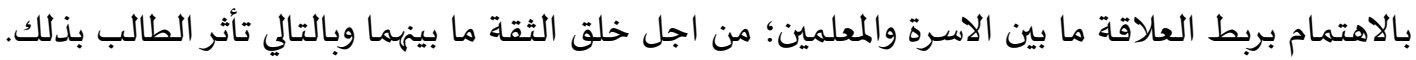

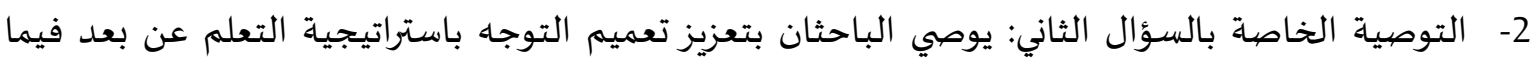
بعد انتهاء أزمة فيروس كورونا لتحقيق قفزات نوعية في النظام التعليمي، من خلال استثمار إيجابيات التعلم

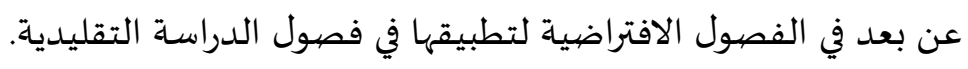

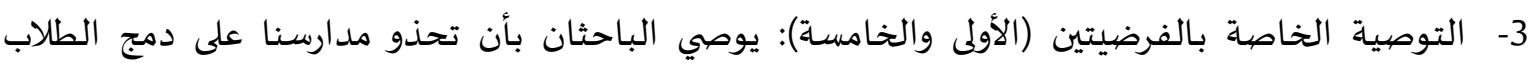
الذكور مع الاناث، من اجل بناء مجتمع متكامل يخلو من العنصرية الذكورية.

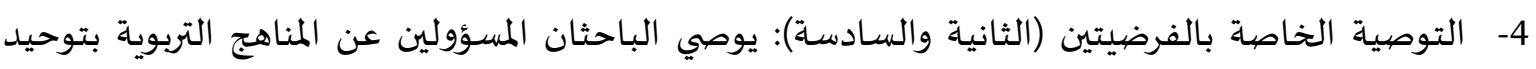

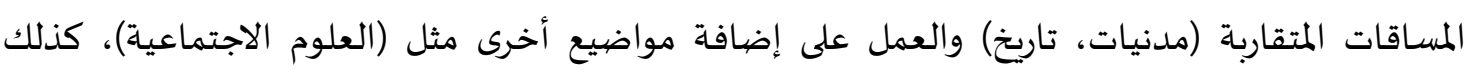

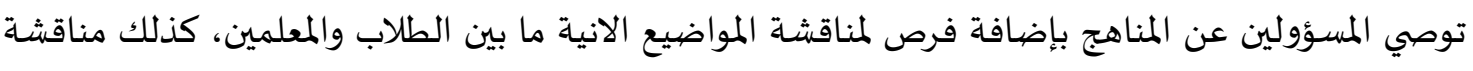
الطلاب فيما بينهم؛ من اجل تعزيز مفاهيمهم في المواضيع الإنسانية.

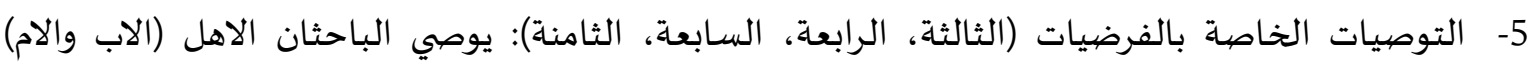

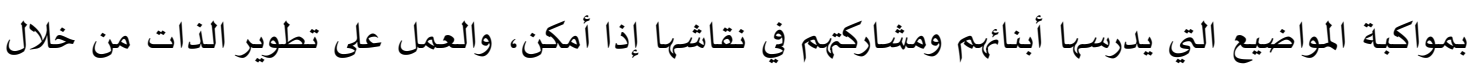
القراءة ومتابعة الأفلام الوثائقية الموثوق بها. 6- التوصيات الخاصة بالتوصية التاسعة: أظهرت النتائج أن هناك علاقة بين الواقع والتطلعات التعات لتعلم طلاب

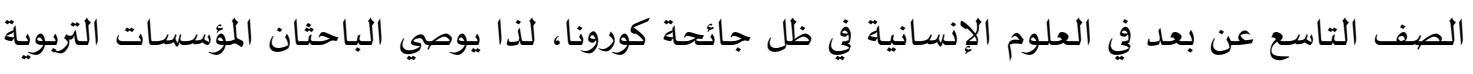

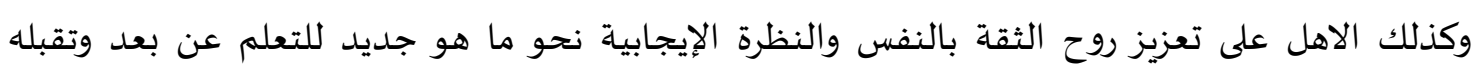
والعمل على تطويره.

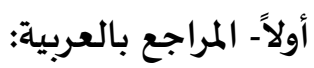

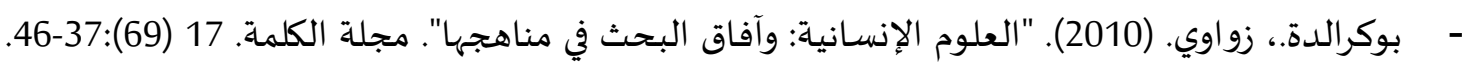

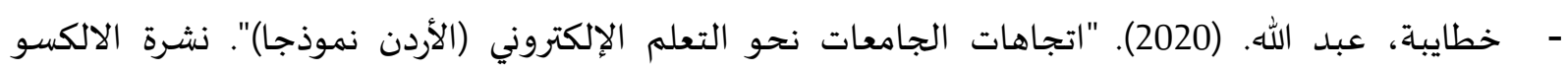
العلمية. عدد (3):27-35. - الدهشان، جمال. (2020). "التعليم ما بعد جائحة كورونا، التحديات والفرص المؤتمر الدولي الرابع لتطوير

التعليم العربي "إدارة التعليم الإلكتروني ضرورة حتمية لحل المشيكاتلات التعليمية الناجمة عن أزمة كورونا"'."

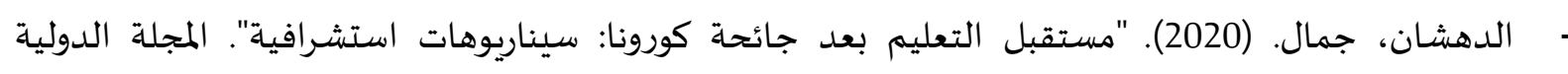
للبحوث في العلوم التربوية .3 (4):105-169. - شديفات، منيرة. (2020). "واقع توظيف التعليم عن بعد بسبب مرض الكورونا في مدارس قصبة المفرق من

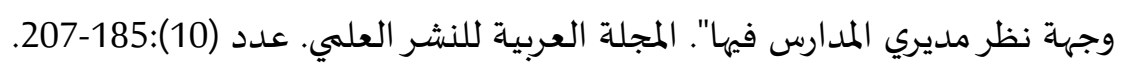

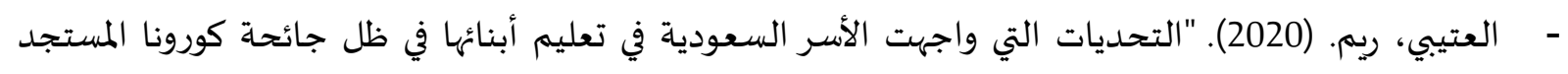

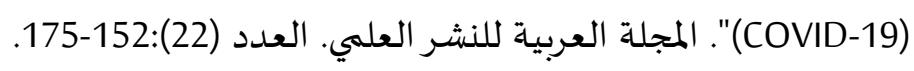


- علي، عواطف إبراهيم. (2012)." استخدام تكنولوجيا المعلومات في التعليم عن بعد". رسالة ماجستير غير منشورة. جامعة الخرطوم (كلية الدراسة عن بعد). السودان. القحطاني، أمل؛ الشّي، حياة؛ امباسي، عزة؛ ناصر، علياء. (2020). "الدافعية ودورها في تفعيل عملية التعلم

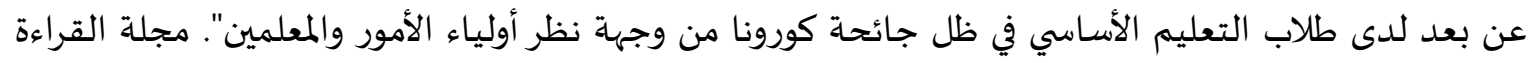
والمعرفة، جامعة عين شمس، كلية التربية، الجمعية المصرية للقراءة والمعرفة المجلد/ العدد (229):275-298. اللمسي، عادل. أحمد، مصطفى. (2020) ."تصور مقترح لتطبيق التعليم الهجين بمدارس التعليم الثانوي العام

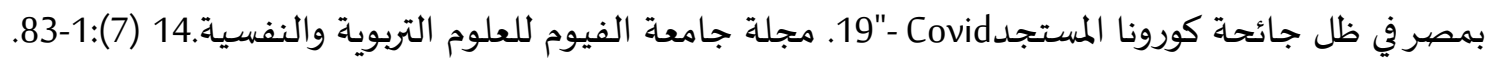
منظمة الأمم المتحدة للتربية والعلم والثقافة. (2020). "التعليم عن بعد -مفهومه أدواته واستراتيجياته، دليل صانعي السياسات في التعليم الأكاديمي والمني والتقني."

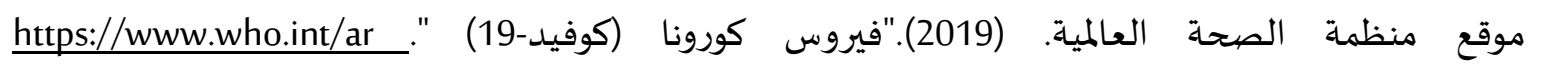
/emergencies/diseases/novel-coronavirus-2019/advice-for-public/q-a-coronaviruses وزارة التربية والتعليم في القدس. (2020) ."عمليات التعلم عن بعد في المؤسسات التعليمية خلال أزمة كورونا،

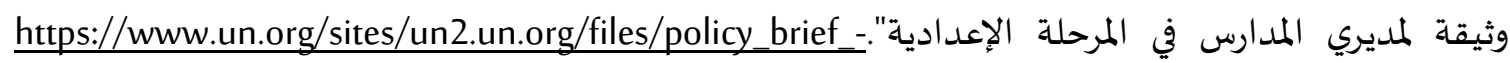
education_during_covid-19_and_beyond_arabic.pdf يحياوي، نجاة؛ خينش، دليلة؛ عزيز، سامياة. (2020). "التعليم عن بعد في ظل جائحة كوفيد19: فطاع التربية

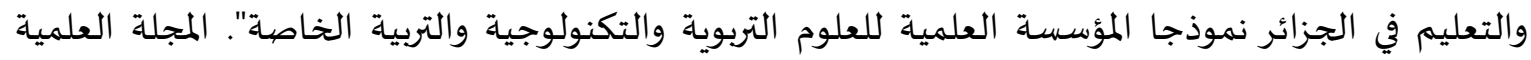
للعلوم التربوية والصحة النفسية، 2 (3):85-104.

\section{ثانياً- المراجع بالإنجليزية:}

- Basilaia ,G,\&Kvavadze,D. Cov-2 (Covid-19) البحوث التربوية، جورجيار:موجود على الموقع الإلكتروني المبرني

- Henriksen, D., Creely, E., Henderson, M. (2020). Folk Pedagogies for Teacher Educator Transitions: Approaches to Synchronous Online Learning in the Wake of COVID-19, Jl. of Technology and Teacher Education. 28 (2), 201-209.

- Sahu P. (2020) Closure of Universities Due to Coronavirus Disease 2019 (COVID-19): Impact on Education and Mental Health of Students and Academic Staff. Cureus 12 (4): e7541. doi:10.7759/cureus.7541

- Yao. J., Rao. J ., Jiang.T. , Xiong. C. (2020). What Role Should Teachers Play in Online Teaching during the COVID-19 Pandemic? Evidence from China. Sci Insigt Edu Front; 5 (2), 517-524. https://doi.org/10.15354/sief.20.ar035. 